\title{
New catalogue of one-apparition comets discovered in the years 1901-1950
}

\section{Comets from the Oort spike}

\author{
Małgorzata Królikowska ${ }^{1}$, Grzegorz Sitarski ${ }^{1}$, Eduard M. Pittich ${ }^{2}$, Sławomira Szutowicz ${ }^{1}$, Krzysztof Ziołkowski ${ }^{1}$, \\ Hans Rickman ${ }^{1,3}$, Ryszard Gabryszewski ${ }^{1}$, and Bożenna Rickman ${ }^{4}$ \\ 1 Space Research Centre of the Polish Academy of Sciences, Bartycka 18A, 00-716 Warsaw, Poland \\ e-mail: [mkr; sitarski; slawka;kazet;kacper]@cbk.waw.pl \\ 2 Astronomical Institute of the Slovak Academy of Sciences, 84504 Bratislava, The Slovak Republic \\ e-mail: pittich@savba.sk \\ 3 Department of Physics and Astronomy, Uppsala University, Box 516, 75120 Uppsala, Sweden \\ e-mail: Hans.Rickman@physics.uu.se \\ ${ }^{4}$ Former employee of Space Research Centre of the Polish Academy of Sciences, Bartycka 18A, 00-716 Warsaw, Poland
}

Received 3 June 2014 / Accepted 3 September 2014

\begin{abstract}
Context. The orbits of one-apparition comets discovered in the early part of the last century have formerly been determined with very different numerical methods and assumptions on the model of the solar system, including the number of planets taken into account. Moreover, observations of the comet-minus-star-type sometimes led to determination of the comet position that are less precise than what we can derive today by using a more modern star catalogue.

Aims. We aim to provide a new catalogue of cometary orbits that are derived using a completely homogeneous data treatment, accurate numerical integration, and a modern model of the solar system.

Methods. We collected the complete sets of observations for investigated comets from the original publications. Then we recalculated the cometary positions for the comet-minus-star-type of observations using the Positions and Proper Motions Star Catalogue, and applied a uniform method for the data selection and weighting. As a final result, new osculating orbits were determined. Secondly, dynamical calculations were performed to the distance of $250 \mathrm{AU}$ from the Sun to derive original and future barycentric orbits for evolution backward and forward in time. These numerical calculations for a given object start from a swarm of virtual comets constructed using our osculating (nominal) orbit. In this way, we obtained the orbital element uncertainties of original and future barycentric orbits.

Results. We present homogeneous sets of orbital elements for osculating, original, and future orbits for 38 one-apparition comets. Non-gravitational orbits are derived for thirteen of them.
\end{abstract}

Key words. catalogs - comets: general - Oort Cloud

\section{Introduction}

The idea of a new catalogue of one-apparition comets was first conceived in the mid-1960s by a team of three astronomers from Warsaw, Maciej Bielicki (1906-1988), Grzegorz Sitarski, and Krzysztof Ziołkowski. The latter two were young enthusiasts of the new computing capabilities that in the first half of the sixties appeared on the horizon for Polish astronomers by gaining access to computers that were called electronic mathematical machines. Bielicki, Sitarski and Ziołkowski began a very long-term project to create and develop a unified package of numerical codes that would perform a fully automated orbital integration of the motion of comets and asteroids to determine their orbits on the basis of astrometric data and investigate their dynamical evolution on any time scales. The numerical codes were gradually verified with examples of comets

\footnotetext{
* All catalogue tables given in appendices (Tables A.1-E.1) are also available at the CDS via anonymous ftp to cdsarc.u-strasbg.fr (130.79.128.5) or via http://cdsarc.u-strasbg.fr/viz-bin/qcat?]/A+A/571/A63
}

(e.g. 22P/Kopff, 26P/Grigg-Skjellerup), which in turn led to the start of the catalogue project in 1967 . This was a very ambitious task in that time in Poland.

The previously existing cometary catalogues contained orbital elements of comets derived from a variety of sources, which means that different methods were used that are characterized by different accuracy and assume different models of the solar system. This new catalogue, in contrast, would contain a uniform set of orbital elements obtained using modern numerical methods and a modern ephemeris of the solar system. The second main idea behind the new catalogue was to determine the orbits of each comet using all the existing positional observations.

Therefore, the most important problems to solve were

- completing all the comet observations in astronomical literature; at that time there was no internet, and it was difficult to access to several of the original publications containing the old observations;

- reducing collected measurements to a single star-catalogue when possible and selecting and weighting these measurements on the basis of mathematically objective criteria; 
- developing the methods for determining the osculating orbits of comets in a uniform manner with the use of accurate numerical integration and a modern model of the solar system.

Thanks to Eduard Pittich from the Astronomical Institute of the Slovak Academy of Sciences at Bratislava, the cooperation between Polish and Slovak astronomers was established for the catalogue project during the twelfth plenary meeting of COSPAR held in Prague in May 1969. Information about this project and the preliminary theoretical solutions of various problems related to data processing and orbital calculations were presented and discussed in a larger international group of specialists during the IAU symposium 45, "The Motion, Evolution of Orbits, and Origin of Comets" held in Leningrad (now Saint Petersburg) in August 1970 . The early publications that directly referred to the idea of a new catalogue outlined how important it would be to uniformly treat astrometric observations and the way they would be selected and weighted (Bielicki 1972; Sitarski 1972; Bielicki \& Ziołkowski 1976). These also described the data treatment and the recurrent power-series method of numerical integration developed by Sitarski (1979a,b).

The Polish-Slovak cooperation focused mainly on collecting positional observations of one-apparition comets. In Poland, the data were collected from the first half of the twentieth century. This activity involved many young astronomers, students, and amateur astronomers, and their work was first coordinated by Tomasz Chlebowski, then still a student of astronomy, and next by Wanda Borodziewicz from the Space Research Centre PAS. In the Chech and Slovak Republics (former Czechoslovakia), where the astronomical libraries had not been as badly destroyed during the Second World War as in Poland, astronomers collected the data for comets of the nineteenth century.

A database of cometary positional observations from the first half of the twentieth century and the development of basic numerical codes associated with the Catalogue project was almost completed in October 1988. At that time, the Polish-Slovak conference "The dynamics of small bodies in the solar system" took place in Warsaw and was largely devoted to the catalogue of one-apparition comets.

Then there was a period of inactivity in the formal work on the catalogue, but the software packages for the orbital calculation were still improved and upgraded for the current dynamical studies of small bodies in the solar system. The adopted research methods, including the method of numerical integration and model of the solar system, were described by Sitarski (1984, 1989, 2002). The developed methods and software packages have been thoroughly tested during all these years, with a resulting number of publications examining the motion of both asteroids and comets, including the non-gravitational effects, for example, Sitarski (1992, 1998) and Rickman et al. (1987).

The final coherent and homogeneous study conducted to determine the orbital motion of comets of the first half of the twentieth century, which is the basis of this part I of the catalogue of one-apparition comets, was carried out during the years 2009-2013.

The paper is organized as follows: in the next section we describe the sample of comets and the data collected for all these objects. Data processing and orbit determination are described in Sect. 3. In some cases we were able to determine the non-gravitational (hereafter NG) orbits. Therefore in Sect. 4, we briefly describe the adopted model of NG acceleration and give some examples of how these NG solutions fit the data in comparison to pure gravitational models. Original and future orbits are discussed in Sect. 5. The article ends with a brief discussion (Sect. 6).

This publication is additionally accompanied by an online catalogue available at ssdp.cbk. waw.pl/LPCs, providing entries for orbital elements of individual comets and for full swarms of the original and future virtual comets (VCs; see Sect. 5) that formed the basis for the detailed analysis of the dynamical evolution. In the future, we plan to insert more graphics there, for example $\mathrm{O}-\mathrm{C}$ time variations.

\subsection{Brief description of the catalogue}

The main part of this catalogue, that is, the tabular material given in this publication, consists of seven tables.

- Tables A.1-A.2 describe the collected observational data and how they were processed,

- Tables B.1-B.2 present homogeneous sets of heliocentric osculating orbits of all investigated comets and sets of nongravitational parameters for comets with determinable nongravitational solutions,

- Table C.1 lists the original and future barycentric inverse semi-major axes and the orbit quality assessment,

- Tables D.1-E.1 include barycentric sets of original and future orbits determined at $250 \mathrm{AU}$ from the Sun.

\section{Sample and general data characteristics}

For this new catalogue we investigated only comets that were discovered in the first half of the twentieth century. The Catalogue of Cometary Orbits (Marsden \& Williams 2008, hereafter MW08) includes 93 long-period comets (orbital period greater than $200 \mathrm{yr}$ ) and 33 parabolic comets (assumed $e=1$ ) discovered in this period.

For the first part of the catalogue, we constructed a sample of near-parabolic comets with original semi-major axes of $1 / a_{\text {ori }}<$ $0.000130 \mathrm{AU}^{-1}$ in MW08, that is, comets of original semi-major axes larger than $\sim 7700 \mathrm{AU}$. This means that we limited ourselves here to comets of good-quality orbits as defined by MW08, that is, according to the orbital quality assessment introduced by Marsden et al. (1978, hereafter MSE). We found 38 comets of $1 / a_{\text {ori }}<0.000130 \mathrm{AU}^{-1}$ in MW08, 32 of which have firstclass-quality orbits (class $1 \mathrm{~A}$ or $1 \mathrm{~B}$ ), and the remaining 6 have second-class-quality orbits (2A or $2 \mathrm{~B})$. In this sample, only six comets have a perihelion distance larger than 3.0 AU, and the highest value is $q_{\text {osc }}=4.2 \mathrm{AU}$ (comet C/1925 F1). The remaining comets from the years 1901-1950 will be the subject of part II of the catalogue. At the moment we have analysed only about $30 \%$ of the objects from this second part.

The positional data for all selected comets were collected from the literature many years ago in Warsaw in cooperation with the Slovakian group from the Astronomical Institute in Bratislava. All collected data are plotted in Fig. 1, where significant selection effects are easily visible, such as the striking predominance of northern sky observations. Characteristics of the collected observational material are given in Cols. (4)-(7) of Table A.1, while the data interval and number of measurements taken to determine the orbit in MW08 are shown in Cols. (8)-(9). In most cases the comets were discovered before perihelion passage, but some were detected just after passing through perihelion (marked as "post" data arc in Col. (4) of Table A.1). Moreover, many comets were followed to much larger heliocentric distances than the heliocentric distance at discovery. This 


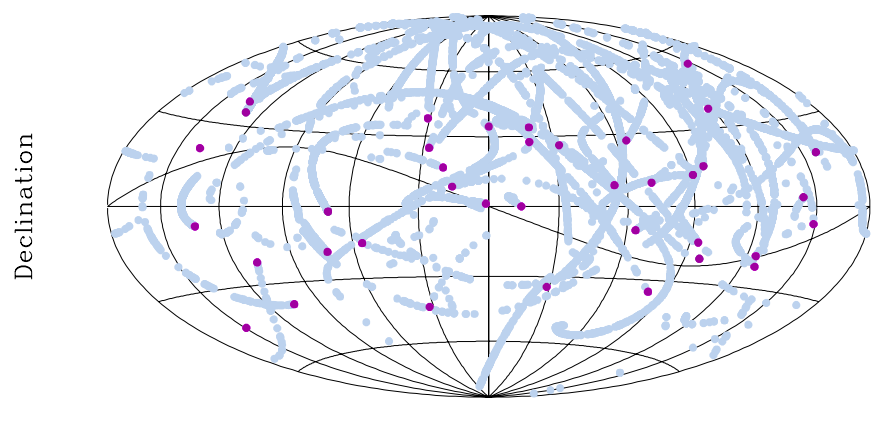

Right ascension

Fig. 1. Overall view on cometary tracks filled by collected astrometric observations in geocentric equatorial coordinate system given in Aitoff projection. The declination is plotted along the ordinate, the right ascension along the abscissa (increasing from zero to 360 degree from the left to right) and the centre of projection is $0^{\circ}$ of declination and $180^{\circ}$ of right ascension. The lines of right ascension and declination are shown at $30^{\circ}$ intervals, and the wavy line shows the projection of the ecliptic onto the celestial sphere. Each positional observation is shown as a light steel-blue point for a given comet, except for the first observation, which is shown as a dark magenta point.

asymmetry in observed heliocentric distances around perihelion is easily visible in Col. (7) of Table A.1. Only in ten cases the heliocentric distance at the moment of discovery is similar to that of the last measurement of the cometary position. For example, only two comets, C/1906 E1 and C/1916 G1, were discovered at distances greater than 5.0 AU from the Sun, while 12 comets were still observed after perihelion passage at similarly large heliocentric distances.

In most cases, we have more observations than the observation sets that were taken to determine the orbits presented in MW08 (compare Cols. (5) and (9) of Table A.1) ${ }^{1}$. Only in two cases $(\mathrm{C} / 1906 \mathrm{E} 1, \mathrm{C} / 1942 \mathrm{C} 1)$ we found fewer literature data than declared in MW08 (Col. (3) of Table C.1).

Comet C/1906 B1 is a special case. In 2003 Kronk (2008) identified two prediscovery observations of this comet. He found that an unknown comet photographed by E. E. Barnard in July 1905 is the comet discovered in January 1906 by Brooks. These observations extend the data interval by about six months. Williams (2005) calculated the orbital elements of the comet based on the completed set of observations (arc of nine months, see also MW08). We supplemented our data for this comet with some positional observations available at the MPC archive (IAU Minor Planet Center Database 2013).

Comet C/1940 R2 is the second special case in this context. We were able to find more data than in MW08 for this comet but, unfortunately, all of them were taken before 1941 April 1, whereas in MW08 the data sequence continues to June 17.

In the remaining cases, however, we have richer observational materials than those listed in MW08 for orbit

\footnotetext{
1 In many old astrometric measurements the position of a comet in right ascension, $\alpha$, and declination, $\delta$, was taken at times separated by a few to several tens of minutes. Then the single observation contains only $\alpha$ or $\delta$. We used such a measurement in one coordinate as a separate observation with one residual where the second residual was rejected for obvious reasons. Generally, we accepted rejection in only one coordinate, $\alpha$ or $\delta$, in our selection procedure when the second coordinate was incorrect. Thus, it is more appropriate to compare the number of residuals taken for our orbit determination (Col. (10) of Table C.1) with those listed in MW08 (taking twice as many data as given in Col. (9) of Table A.1).
}

determination. In many cases, our collected data are even several times more numerous, for instance for comets C/1902 R1, C/1902 X1, C/1904 Y1, C/1912 R1, C/1913 Y1, C/1914 F1, C/1919 Q2, C/1932 M1, C/1937 C1, and C/1950 K1. Moreover, for almost all comets we also have data of comet-minus-star type that allow us to correct the cometary positions for a newer catalogue than was formerly available. Starting with orbit determination in this project, we decided to use the Positions and Proper Motions Star Catalogue (PPM catalogue) that is the successor of the SAO catalogue and contains precise positions (in the J2000/FK5 coordinate system) of almost 400000 stars located on the whole sky and is almost complete to $V=9.5$ with about 25 per cent of stars fainter than $V=10^{\mathrm{m}}$. The PPM catalogue was very helpful for finding the star positions for the purpose of very old observations of comets (Gabryszewski 1997). During this project we found that it is also very helpful for the sample of comets discovered in the years 1901-1950 (see next section).

\section{Data processing and osculating-orbit determination}

Old cometary observations were prepared by observers as apparent positions in right ascension and declination or as reduced positions for the epoch of the beginning of the year of a given observation; the observations were much more rarely reduced to a more distant epoch. This is a huge advantage of these data, because we were able to uniformly take into account all necessary corrections associated with the data reduction to the standard epoch.

Moreover, as was already mentioned, many observers have also published the comet-minus-star measurements, $\left(\boldsymbol{\top}^{\top}-\star\right)$. Thus, the most original observations of a comet's positions relative to the reference stars have allowed us to recalculate new positions of the comet using a more modern star catalogue (PPM catalogue).

This caused the data processing and each cometary orbit determination to consist of three steps.

At the beginning of the first step we determined the preliminary pure gravitational (hereafter GR) osculating orbit using only a selection procedure based on Chauvenet's criterion (fewer than one hundred observations in the given set of data) or Bessell's criterion (more than one hundred observations). For a description of these two criteria, see Bielicki \& Sitarski (1991) and Królikowska et al. (2009). Next, we extracted all measurements with comet-minus-star $\left(\boldsymbol{\tau}^{-} \star{ }^{-}\right)$data. The numbers of this type of observations are given in Col. (2) of Table A.2. Assuming that the $\left(\boldsymbol{\nabla}^{\top}-\star\right)$ data are measurements that cannot be changed, we recalculated the new comet position for these observations in right ascension and declination using the PPM catalogue. The detailed procedure to recalculate the comet's position is described by Gabryszewski (1997), where the successful application to four sets of cometary measurements taken between the years 1860-1930 is also presented. In all cases we found that this procedure improved the orbit determination by (i) reducing the root mean square (rms) residual and/or by (ii) changing the number of residuals. This can be seen by comparing rms and number of residuals for the osculating orbit determined from the whole set of measurements (Col. (5) of Table A.1) before applying the PPM procedure (Cols. (5)-(6) of Table A.2) with rms and number of residuals after the PPMprocedure application (Cols. (7)-(8) of Table A.2). The recalculated cometary positions were selected using the same criterion 
and procedure as for the original data. For example, the rms for comets C/1903 M1 (59\% of ( $\boldsymbol{\top}-\star$ ) data improved spectacularly: the rms decreased from 4".39 to 3.'76), as well as for C/1907 E1 (72\%, 4". $14 \searrow$ 2'.82), for C/1919 Q2 (75\%, 3"'38 \2".58), for C/1932 M1 (48\%, 3".52 \2.'89), and for C/1937 C1 (45\%, 4". $42 \searrow 3$." 49).

We also collected many data consisting of only $\left(\boldsymbol{\tau}^{\top} \star \star\right)$ measurements, that is, without calculated cometary positions. In these situations we interpolated a preliminary comet position from the observations taken just before and after such a measurement. Using this preliminary position of the comet, we tried to find the actual star position on the basis of the PPM catalogue and then the actual comet position. In some cases this method was successful and allowed us to significantly increase the number of data, as in the case of C/1916 G1 (number of residuals increased by $10 \%), \mathrm{C} / 1921 \mathrm{E} 1$ (11\%) and C/1922 U1 (12\%); these three cases are marked by the icon ${ }^{\top}$ in Col. (8) of Table A.2).

At the end of this step we determined the osculating orbit from data modified following the PPM catalogue, using the pure selection procedure based on Chauvenet's or Bessel's criterion (depending on the number of measurements in the data set, as mentioned before). Additionally, when there were very many data, we selected data before and after perihelion passage, independently. This is a very good way to select data to estimate the possibility of detecting NG effects in the cometary motion. When the rms derived from the whole data set using the pure GR model exceeds the rms for the two legs of the GR orbit determined independently, this indicates that the NG effects will be easily determinable in the motion of the comet.

In the second step we determined the osculating orbit from the data recalculated following the PPM catalogue, using the selection and weighting procedure simultaneously with the orbit determination. We found earlier that the weighting procedure is crucial for the orbit fitting (see for example Królikowska et al. 2009; Królikowska \& Dybczyński 2010). Here, we confirm this conclusion also for comets discovered in the first half of the twentieth century. We decided, however, not to weight observations for smaller data sets (fewer than one hundred measurements). Thus, the data were not weighted for C/1914 M1, C/1940 S1, C/1944 K2, and C/1948 T2. We made an exception for $\mathrm{C} / 1942 \mathrm{C} 2$, where the model presented here was weighted since the observations were taken only at four different observatories. Generally, the weighting procedure results in lower rms; for C/1902 X1, for example, the rms decreased from 3". 37 (1301 residuals, preliminary solution, see Col. (7) of Table A.2) to 1.' 66 (1307 residuals, Col. (9) of Table C.1), for C/1916 G1 from 3.' 14 (826 residuals) to 1'.97 (823 residuals, GR solution), or for C/1942 C2 from 1'.65 (88 residuals) to 1'.57 (88 residuals).

Additionally, in some special cases we used a more restrictive criterion of data selection for the final solution than for the preliminary solution. The final non-weighted solution for $\mathrm{C} / 1940 \mathrm{~S} 1$ (the poorest quality of orbit in this catalogue), for example, was based on data selected according to Bessel's criterion, and the resulting rms is significantly lower than the preliminary one (compare Col. (9) of Table C.1 and Col. (7) of Table A.2).

The rms and number of residuals resulting from the final selection and weighting procedure are given in Cols. (9)-(10) of Table C.1, while elements of these pure GR osculating orbits are listed in Table B.1. Our data processing resulted in reasonably few residual rejections in comparison to MW08 (compare Col. (10) of Table C.1 with twice as many observations given in Col. (10) of Table A.1). Our selecting and weighting procedure gives fewer than $22 \%$ of rejected residuals for comets investigated here, and the mean percentage of rejected residuals is 17.6. The estimates of data percentage used for osculating orbits listed in MW08 are shown in Col. (3) of Table C.1, where numbers are given in comparison to data sets collected and used in this investigation. Except for the two comets already mentioned in Sect. 2 (C/1906 E1 and C/1942 C1), these percentages taken into account to determine the orbit are significantly lower than ours, below $50 \%$ for 20 comets, and even below $30 \%$ for five of them.

Table C.1 also includes the general quality characteristics of the osculating-orbit determinations. The orbit quality assessment given in MW08 and taken according to the original MSE method is presented in Col. (2). The same MSE method applied to our solution of osculating orbits leads to a different orbit quality assessment for comets C/1902 X2 (1A instead of 1B) C/1906 E1 (1A instead of 1B), C/1914 M1 (1B instead of 1A) C/1940 S1 (2A instead of 2B), C/1941 K1 (1A instead of 1B), and C/1942 C1 (1A instead of 1B), where we compare the MW08 orbit quality with our pure GR solution (see Col. (11) of Table C.1). In almost all these cases our osculating orbits are of better quality according to the MSE method of orbit quality assessment. In Col. (12) of Table C.1 we list the new quality assessment introduced by Królikowska \& Dybczyński (2013). This new orbit quality estimate is based on the original MSE method, but is slightly more restrictive and better diversifies than the MSE method, especially concerning recently discovered objects that are observed using modern techniques. In the following discussion, we refer to this new orbit quality estimate.

In the third step we made an attempt to determine the NG effects in the motion of each comet. Once again, each individual set of astrometric data was selected and weighted simultaneously with the iterative process of NG orbit determination. The model of NG motion is described in the next section. In the present investigation we were able to determine $\mathrm{NG}$ effects in the motion of thirteen comets, that is, in $34 \%$ of the comets investigated here. These comets are indicated by grey shading in Table A.1.

All the numerical calculations presented here are based on the Warsaw ephemeris DE405/WAW (Sitarski 2002), that is, a numerical solar system ephemeris, which is consistent at a high accuracy with the JPL ephemeris DE405 (Standish 1998). The equations of motion were integrated using the recurrent powerseries method (Sitarski 1989), taking into account the perturbations by all planets and including relativistic effects.

\section{Non-gravitational acceleration}

To determine the NG cometary orbit we applied the standard formalism proposed by Marsden et al. (1973, hereafter MSY) where the three orbital components of the NG acceleration acting on a comet are expressed by a function $g(r)$ symmetric relative to perihelion,

$$
\begin{aligned}
& F_{i}=A_{i} g(r), \quad A_{i}=\text { const. for } i=1,2,3, \\
& g(r)=\alpha\left(r / r_{0}\right)^{-2.15}\left[1+\left(r / r_{0}\right)^{5.093}\right]^{-4.614},
\end{aligned}
$$

where $F_{1}, F_{2}, F_{3}$ represent the radial, transverse, and normal components of the NG acceleration, respectively, and the radial acceleration is defined outward along the Sun-comet line. The normalization constant $\alpha=0.1113$ gives $g(1 \mathrm{AU})=1$; the scale distance $r_{0}=2.808 \mathrm{AU}$. From orbital calculations, the NG parameters $A_{1}, A_{2}$, and $A_{3}$ were derived together with six orbital elements within a given time interval (numerical methods were originally described by Sitarski 1984). The standard 
M. Królikowska et al.: New catalogue of one-apparition comets
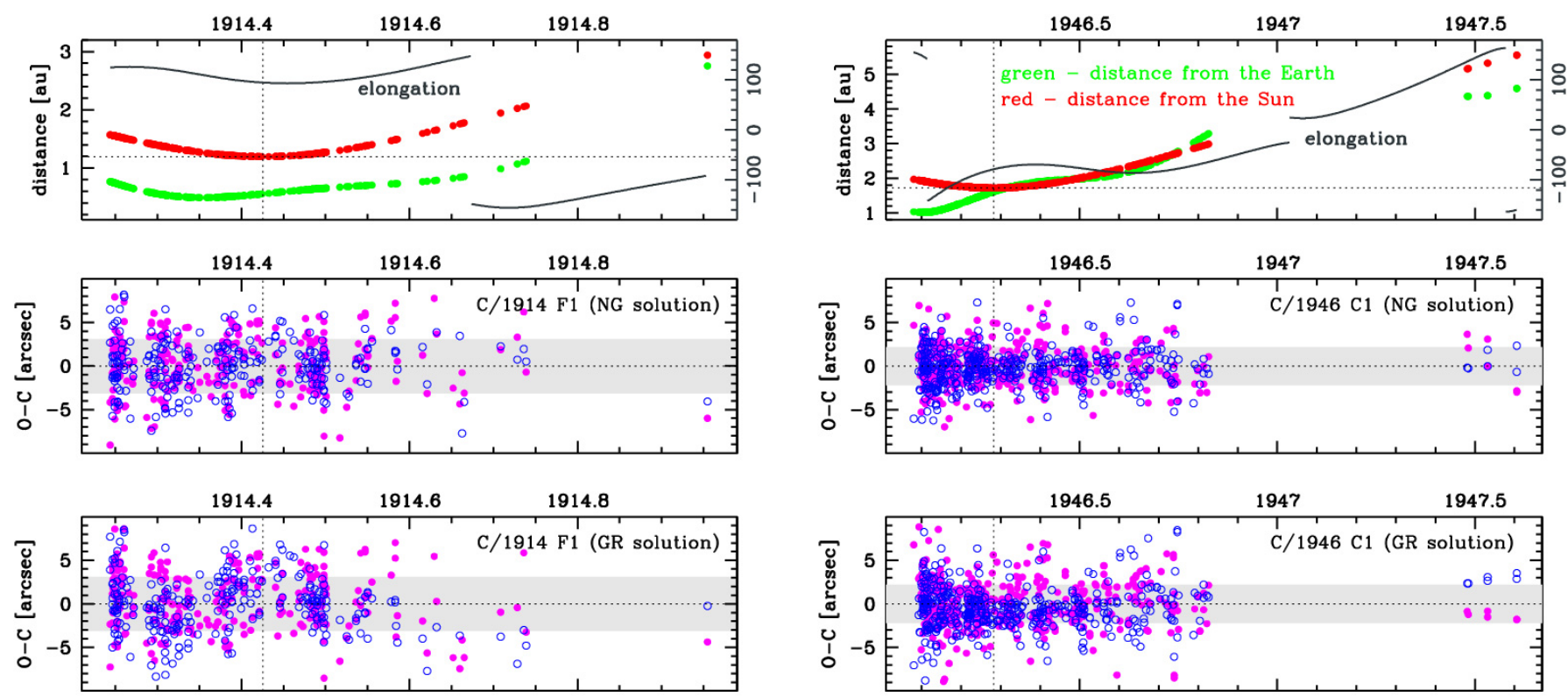

D a t e

D a t e

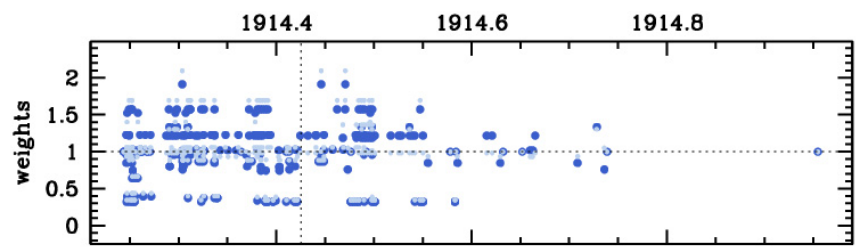

D a t e

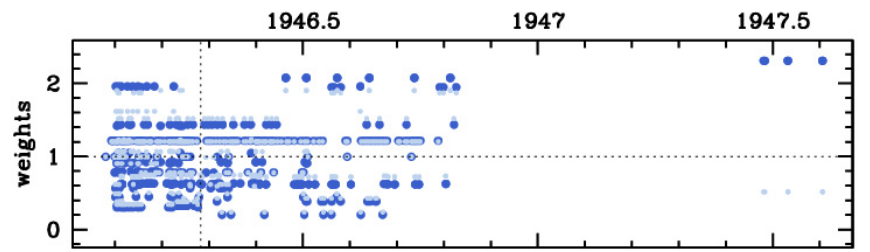

D a t e

Fig. 2. O-C diagrams for comets C/1914 F1 Kritzinger (left-hand panels) and C/1946 C1 Timmers (right-hand panels). Upper panels show the time distribution of positional observations with corresponding heliocentric (red curve) and geocentric (green curve) distance at which they were taken (left-hand vertical axes). Horizontal dotted lines show the perihelion distance and vertical dotted lines the moment of perihelion passage. Dark grey curves represent the change of the comet's elongation within the observed time intervals (right-hand vertical axes range from -180 to 180 degrees). The second panels from the top present the $\mathrm{O}-\mathrm{C}$ based on NG solutions, the third panels show O-C based on a pure GR orbit. Residuals in right ascension are shown as magenta dots and in declination as blue open circles. The lowest panels show the comparison between the normalized weights of data between NG solution (dark blue points) and GR solution (light steel-blue points).

NG model assumes that water sublimates from the whole surface of an isothermal cometary nucleus. An asymmetric model of NG acceleration is derived by using $g(r(t-\tau))$ instead of $g(r(t))$ (Yeomans \& Chodas 1989; Sitarski 1994). This last model introduces an additional NG parameter $\tau$ - the time displacement of the maximum of the $g(r)$ relative to the moment of perihelion passage. We found that only the symmetric model of NG motion was applicable for the comets investigated here.

Using the formalism described above, we found satisfactory NG models for thirteen of the 38 investigated near-parabolic comets. The NG parameters found for all these comets are presented in Table B.2. We noticed some traces of NG effects in the motion of some other comets, but we decided to present here only the NG solutions where we noticed an improved orbit fitting in comparison to a pure gravitational orbit. This improved fitting was measured by three criteria (Królikowska \& Dybczyński 2013):

- decrease in rms residual,

- overcoming or reducing the improper trends in $\mathrm{O}-\mathrm{C}$ time variations,

- increasing the similarity of the $\mathrm{O}-\mathrm{C}$ distribution to a Gaussian distribution.
Solutions that include the NG effects in the model of motion are highlighted by grey shading in Tables A.1, B.1, C.1, D.1, and E.1. The rms residual for all NG solutions presented here is lower than the GR solutions (Col. (9) of Table C.1). In the following two subsections we discuss some examples that illustrate the improved time variation and statistical distribution of $\mathrm{O}-\mathrm{C}$ residuals when $\mathrm{NG}$ accelerations are included in the comet motion.

\subsection{O-C time variations}

Two examples of how the NG model of motion improves the $\mathrm{O}-\mathrm{C}$ vs. time diagram are presented in Fig. 2 for comets $\mathrm{C} / 1914 \mathrm{~F} 1 \mathrm{Kritzinger}\left(0.48 \mathrm{yr}\right.$ data span, $\left.q_{\mathrm{osc}}=1.20 \mathrm{AU}\right)$ and C/1946 C1 Timmers (1.52 yr data span, $\left.q_{\text {osc }}=1.72 \mathrm{AU}\right)$, which have second- and first-class orbits, respectively.

\subsubsection{NG solutions for comets of second-class orbits}

Comets of second-class orbits need special care during the NG solution because of the relatively large rms residuals. We were surprised to find NG trends in data for five such comets. 
Among these five are three comets (C/1906 B1, C/1911 S3 and C/1921 E1) with hyperbolic original, barycentric orbits. We chose $\mathrm{C} / 1914 \mathrm{~F} 1$, which has $2 \mathrm{a} / 2 \mathrm{~b}$ class GR/NG orbits, to visualize the differences between GR and NG solutions in $\mathrm{O}-\mathrm{C}$ time variations. However, we also discuss in detail the differences between NG and GR solutions for the remaining four comets of second-class orbits.

The O-C time variations for C/1914 F1 are compared in the left-hand part of Fig. 2. One can see wavy trends with time in declination for the purely gravitational solution (blue open dots in the third panel from the top). Additionally, almost all residuals in right ascension and declination from 1914 August 26 to the last observation are negative. Both trends disappear in the NG model of motion (second panel). This improvement in $\mathrm{O}-\mathrm{C}$ time variations is accompanied by a reduced rms residual from 3". 33 to 3"' 12 (see Table C.1). Moreover, the O-C distribution for the NG orbit is perfectly Gaussian with $\chi^{2}=15.9$ for 18 degrees of freedom, while the critical $\chi^{2}(18,0.05)$-value associated with the number of degrees of freedom (18) and assumed significance level (0.05) equals 28.9. The purely gravitational orbit gives a poorer fitting to a normal distribution (with $\chi^{2}=24.7$ for 18 degrees of freedom).

Thus, the NG orbit seems to be a more adequate solution for $\mathrm{C} / 1914 \mathrm{~F} 1$, although the NG osculating orbit is determined with very poor accuracy ( $2 \mathrm{~b}$ class). It yields an original inverse semimajor axis of $(600 \pm 152) \times 10^{-6} \mathrm{AU}^{-1}$, that is, far beyond the Oort spike, but within 3 sigma combined error, this value is consistent with the $1 / a_{\text {ori }}=(57 \pm 28) \times 10^{-6} \mathrm{AU}^{-1}$ that results from a purely GR solution. In our opinion this NG orbital solution better describes both the actual motion of this comet and our actual knowledge of the orbital elements.

Generally, the NG model of motion (if determinable) is always closer to reality. However, in this model we always need to determine additional parameters together with the orbital elements. Thus, the uncertainties of orbital elements of a NG orbit are usually larger than those of a GR orbit for the same comet. Nevertheless, the NG solution with its larger uncertainties more adequately describes our actual knowledge of the dynamics of an individual comet.

This argument was also an important reason to give NG solutions for two other comets of second-class orbits, C/1911 S3 (0.38 yr data span, $\left.q_{\text {osc }}=0.303 \mathrm{AU}\right)$ and C/1937 N1 (0.49 yr data span, $\left.q_{\text {osc }}=0.86 \mathrm{AU}\right)$. In both cases, the data interval is about as short as for C/1914 F1. Additionally, the data structure is similar for all three comets.

In the C/1911 S3 data, the gap in observations toward the end of data goes from 1911 October 29 to 1912 Jan. 28 with five more observations from January 29 to February 17 taken by C.D. Perrine at Cordoba (National Observatory, Argentina). The eccentricity of the osculating orbit determined by us $(e=$ 1.000174 on the basis of 246 residuals) is closer to the value derived originally by Grubissich $(1952, e=1.000170$ on the basis of 128 measurements) than to that obtained by MSE and given in MW08 ( $e=1.000147$, on the basis of only 66 observations).

For C/1937 N1 a similar lack of data exists from 1937 October 6 to December 29, and the last single measurement was taken on December 30 by J. Bobone also at Cordoba. The importance of the last measurements of data is evident in both cases. We noticed a better fitting of the terminal data in NG solutions for both comets, but with significantly less improvement in overall O-C time variation for C/1937 N1 than for C/1914 F1. We conclude that $\mathrm{NG}$ effects are visible mainly in the decrease of rms residual (see Col. (9) of Table C.1).
Similar to the C/1914 F1 case, NG solutions of C/1911 S3 and $\mathrm{C} / 1937 \mathrm{~N} 1$ result in significant shifts of $1 / a_{\text {ori }}$ to more positive values (Sect. 5).

Two more comets with determinable NG effects and secondclass orbits are C/1906 B1 and C/1921 E1. Both comets were observed longer than those discussed above and have a gap in observations at the beginning (C/1906 B1, six-month lack of data) or close to the end $(\mathrm{C} / 1921 \mathrm{E} 1$, three-month lack of observations) of data sequences. This data structure causes two prediscovery observations in July 1905 to extend the data period from three to nine months for C/1906 B1. Thus, these two prediscovery observations are crucial for determining the NG effects in the motion of this comet. In the second case, the situation is slightly different because at the end of data we have a sequence of four observations from 1921 October 2 to 1921 November 26. All of them were taken by W.H.W. Baade, who was the only observer that followed the comet after the three-month gap in data caused by the comet's conjunction with the sun. In the GR solution all residuals are negative in both right ascensions and declination. This trend disappears for the NG orbit.

\subsubsection{NG solutions for comets of first-class orbits}

Of the eight comets from this group we selected C/1946 C1 for the detailed discussions because it has a characteristic data structure with a large gap at the end of the time sequence of observations (right panel of Fig. 2). In this case, the six measurements taken by H. M. Jeffers using the 36-inch Crossley reflector at Lick Observatory (Mount Hamilton) are crucial for osculating orbit determinations. He photographed the comet in 1947 on June 24-25, July 13, and August 9. These observations extended the observation interval by almost ten months. In the third right-side panel from the top, all six measurements show a trend towards increasingly negative residuals in right ascension and increasingly positive residuals in declination for a purely GR solution. In this case the rms residual decreases from 2 '.53 (GR solution) to 2". 17 (NG solution, see Table C.1).

The bottom panels of Fig. 2 show a close similarity in normalized weights of data between the NG solution (dark blue points) and the GR solution (light steel-blue points) for the entire data interval (C/1914 F1) or almost all measurements (C/1946 C1). This merits a brief comment. Normalized weights obtained in the GR model for the measurements taken at Mount Hamilton (about 0.5) suggest that these data are of lower accuracy than the average subset of measurements in this data set, while assuming a NG model of motion, we derive that these data fit the model best of all groups of measurements taken for this comet. This is an additional indication that the NG model better describes the actual motion of C/1946 C1.

This behaviour of weights is rather typical for all comets investigated here. However, sometimes there are even trends in weights for GR models in contrast to NG models (see Sect. 4.2).

\subsection{O-C distributions}

Two other examples provide a comparison of O-C distributions between three types of models: (i) the GR model determined using selected data; (ii) the GR model based on selected and weighted data; and (iii) the NG model also based on selected and weighted data. Observations were always individually selected and/or weighted during each process of orbit determination for each model (see bottom panels in Fig. 2). The upper 


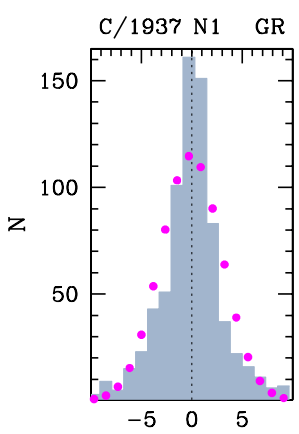

residuals $[\operatorname{arcsec}]$ $\chi^{2}=98.1$

18

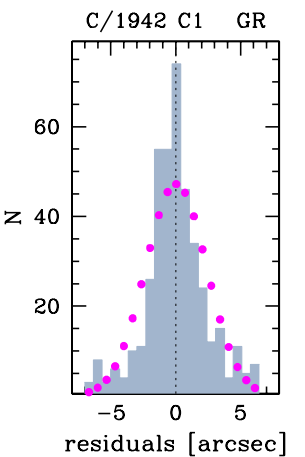

residuals $[\operatorname{arcsec}]$

$\chi^{2}=55.2$

18

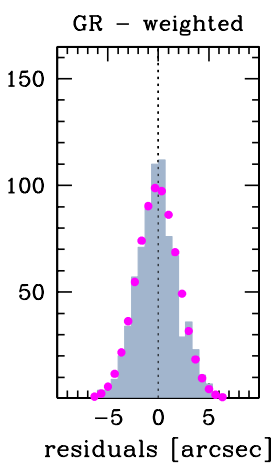
$\chi^{2}=40.9$
NG - weighted

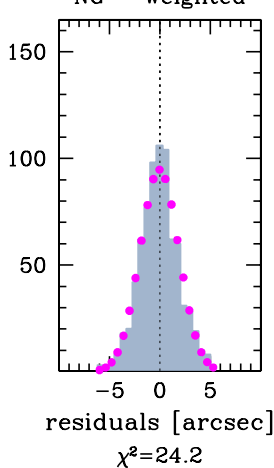

f $\mathrm{r}$ e e d o m
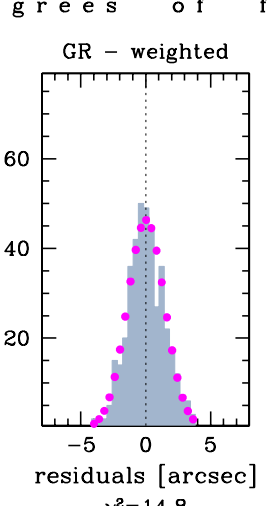

$\chi^{2}=14.8$
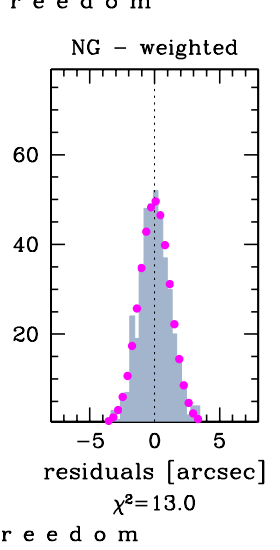

Fig. 3. O-C residual distributions taken for orbit determination for comets C/1937 N1 Finsler (upper panels, second-class GR/NG orbits) and C/1942 C1 Whipple-Bernasconi-Kulin (lower panels, first-class GR/NG orbits). For both comets three types of solutions are shown, from left to right: pure GR solution based on non-weighted data, pure GR solution based on weighted data, and NG solution derived using weighted data. The best-fitting Gaussian distributions are shown by magenta dots, each chosen to lie exactly in the middle of a histogram bin.

panels of Fig. 3 display the residual distributions for C/1937 N1 Finsler and the lower panels those for C/1942 C1 WhippleBernasconi-Kulin (here, we present the combined distributions of the residuals in right ascension and declination since in our weighting procedure we applied the simplifying assumption of equal weight in right ascension and declination for an individual measurement). In both cases, about $8-9 \%$ of the residuals are rejected in all three models, while the orbit of C/1937 N1 in MW08 was determined using only about 50 per cent of the data collected in the literature by us, and for C/1942 C1, we have fewer observations than declared in MW08.

The best-fitting normal distribution for the data sets of both comets deviates significantly when all measurements were taken with equal weights. Moreover, the asymmetry of the residual distribution is noteworthy (leftmost distributions in both sets of panels of Fig. 3). The improvement of the fit to a Gaussian distribution is remarkable when we include the weighting procedure in the GR orbit determination in both cases. The goodness of the fits of the derived $\mathrm{O}-\mathrm{C}$ distributions to Gaussians was measured by the Pearson chi-squared test. Additionally, we calculated the kurtosis (related to the fourth moment of the distribution) and skewness (related to the third moment), and thus controlled whether/how the deviations from the normal distribution decrease when NG effects are included in the model of motion. The values of $\chi^{2}$-test and the number of degrees of freedom are presented below each histogram in Fig. 3 .

As was mentioned before, the critical $\chi^{2}(18,0.05)$ value equals 28.9. This means that in for C/1937 N1 both GR solutions give residual distributions inconsistent with a hypothesized normal distribution, while for $\mathrm{C} / 1942 \mathrm{C} 2$ the residual distributions for GR-weighted solution $\left(\chi^{2}=14.8\right)$ fit a normal distribution very well. For C/1937 N1 the deviation can be interpreted to mainly result from the inadequacy of the GR model. Hence, NG effects may be suspected in the motion of this comet. When these are included in the model, the resulting distribution of residuals gives $\chi^{2}=24.2$, indicating that the residual distribution for the NG model is consistent with a normal distribution at the assumed significance level of 0.05. This is different for C/1942 C1. Already the GR solution based on weighted data gives an excellent fit to a normal distribution, similarly as the NG solution does.

The examples given in Fig. 3 are representative for all comets with determinable NG effects. Thus, in some cases, we do not observe improvements in the fit to a normal distribution between GR and NG models. However, the decrease of rms and O-C time variations indicate that the NG model better represents the data set than the GR solution. Additionally, sometimes we noticed that the weights determined in a GR model try to compensate for trends in residuals by a more of less systematic decrease of weights for measurements at the end of the data interval. In the NG models these trends disappear.

\section{Original and future orbits}

To derive original and future reciprocal semi-major axes for each comet, we performed dynamical calculations backward and forward in time out to $250 \mathrm{AU}$ from the Sun, that is, to a location where planetary perturbations are completely negligible (Todorovic-Juchniewicz 1981). In the present investigation of dynamical evolution, the numerical calculations for a given object start from a swarm of virtual comets (hereafter VCs) constructed using the osculating orbit (so-called nominal osculating orbit) determined in the respective model shown in Table B.1. For comets with determinable NG effects, we calculated two types of evolution: the pure GR evolution starting from the purely gravitational osculating orbit, and the NG evolution starting from the NG osculating orbit.

Each individual swarm of starting osculating orbits consists of $5001 \mathrm{VCs}$ including the nominal orbit and is constructed according to the Monte Carlo method proposed by Sitarski (1998), where the entire swarm fulfils the Gaussian statistics of fits to positional data for a given osculating orbit determination. All 1/adistributions and the distributions of other orbital elements of the analysed swarm of VCs were still perfectly Gaussian at $250 \mathrm{AU}$ from the Sun.

Hence, we are able to determine the uncertainties of original and future orbital elements, including the reciprocal semimajor axes, by fitting each original/future swarm of VC orbital elements to a Gaussian distribution. These uncertainties of orbital elements are given together with original/future elements in Cols. (3)- (9) of Table D.1/E.1. Additionally, Table C.1 shows differences in original and future values of 1/a between MW08 (Cols. (4) and (6)) and our investigation (Cols. (7) - (8)).

Assuming that orbits listed in MW08 have intrinsic errors (uncertainties) on the same level as ours, we found that our $1 / a_{\text {ori }}$ for GR orbits are consistent within about combined 3 sigma with those given in MW08 for almost all comets investigated here. This fact is illustrated in Figs. 4 and 5. In both figures our GR solutions for comets of first-class orbits (1a or 1b) are plotted in 


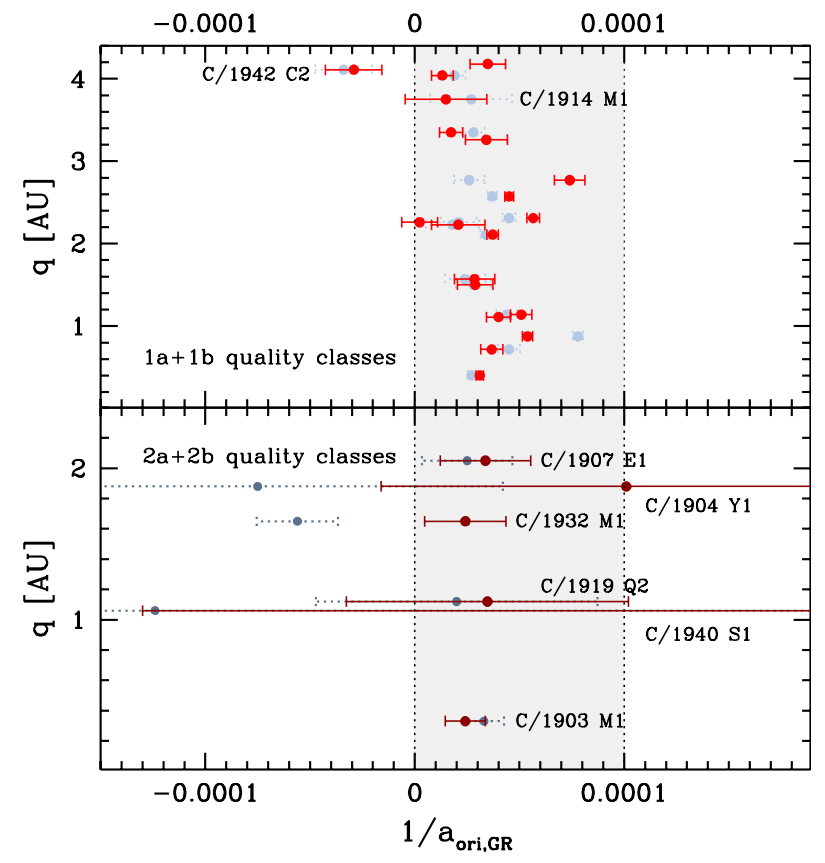

Fig. 4. Comparison between $1 / a_{\text {ori,GR }}$ (red and dark red points and their error bars) for 25 comets with indeterminable NG effects and values given in MW08 (light and dark steel-blue points), where the uncertainties were assumed to be the same as ours (dotted error bars). The upper panel presents comets of first-class orbits, while the bottom panel shows six comets having second-class orbits according to the new, more restrictive quality assessment. C/1903 M1, C/1904 Y1, and $\mathrm{C} / 1940 \mathrm{~S} 1$ belong to the comets with the shortest intervals of observations among all investigated objects (less than $0.42 \mathrm{yr}$ ). On the other hand, three comets with the largest $1 / a$-uncertainties among first-class orbits (C/1914 M1, C/1942 C2 and C/1944 K2) were observed for more than $1 \mathrm{yr}$.

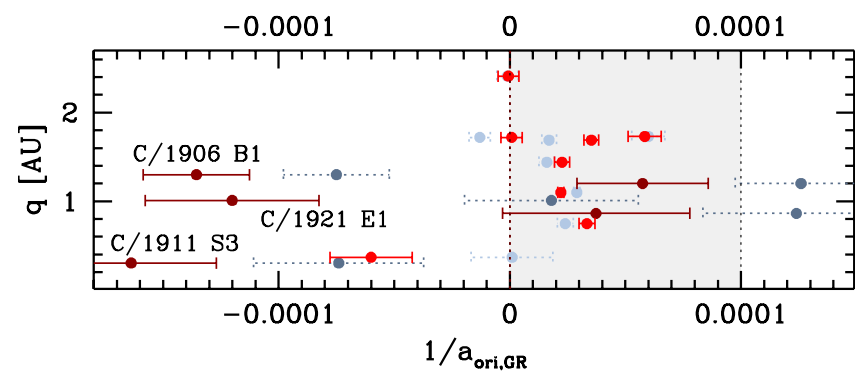

Fig. 5. Same as in Fig. 4 for GR solutions for 13 comets where we determined NG effects (compare also with Fig. 6). Four negative $1 / a_{\text {ori,GR }}$ belong to comets from left to right: $\mathrm{C} / 1911 \mathrm{~S} 3$ ( $q=0.303 \mathrm{AU}$, orbital quality class: 2a/2b, MW08: 2A), C/1906 B1 $(q=1.30 \mathrm{AU}$, class: 2a, MW08: 1B), C/1921 E1 $(q=1.01$ AU, class: 2a, MW08: $1 \mathrm{~B})$ and C/1940 R2 ( $q=0.368$ AU, class: 1b, MW08: 1B). Two more points with large uncertainties of $1 / a_{\text {ori,GR }}$ represent comets $\mathrm{C} / 1937 \mathrm{~N} 1$ $(q=0.863$ AU, class: 2a, MW08: 2A) and C/1914 F1 $(q=1.20 \mathrm{AU}$, class: $2 \mathrm{a} / 2 \mathrm{~b}, \mathrm{MW} 08 \mathrm{~A} \mathrm{~A})$. Our values of the original inverse semi-major axis for $\mathrm{C} / 1946 \mathrm{U} 1(q=2.41 \mathrm{AU})$ and $\mathrm{C} / 1937 \mathrm{C} 1(q=1.73 \mathrm{AU})$ are almost the same as in MW08; hence the steel-blue points are invisible.

red, and those of second-class orbits $(2 \mathrm{a}$ or $2 \mathrm{~b})$ in dark red. The $1 / a_{\text {ori }}$ values in MW08 are shown by light steel-blue points with dotted assumed error bars.

With the classic MSE paper, it became clear that NG effects are important for determining the original inverse semi-major axis for long-period comets. In a series of papers, Królikowska (2001, 2004, 2006) showed that by including the NG accelerations into the model of motion, slightly different osculating
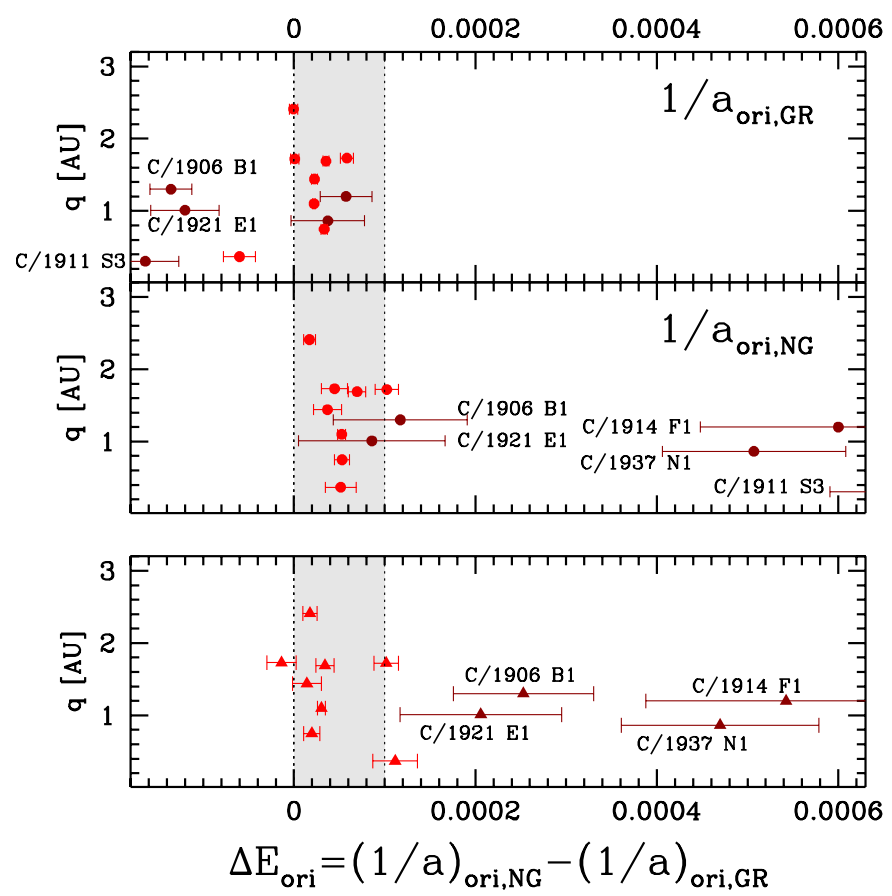

Fig. 6. Shifts of $1 / a_{\text {ori }}$ caused by the NG acceleration for thirteen comets from the period $1901-1950$. The five largest uncertainties of $1 / a_{\text {ori,NG }}$ (middle panel) and $\Delta E_{\text {ori }}$ (lowest plot) belong to comets of second-class orbits.

orbits were derived than when assuming purely gravitational motion, and these subtle differences can significantly change the original semi-major axes of these near-parabolic comets. This effect is also clearly visible for comets investigated here. The differences between the reciprocal semi-major axes derived in the NG and GR models of motion are illustrated for 13 comets examined here in Fig. $6(\mathrm{C} / 1911 \mathrm{~S} 3$ is outside the right border in the lowest panel). In this sample of comets with detectable NG effects there are eight comets with first-class orbits (1a and $1 \mathrm{~b}$ ) and five with second-class orbits. The latter five are recognizable in Fig. 6 by dark red colour and significantly larger uncertainties of $1 / a_{\text {ori }}$ than the remaining eight comets.

Limiting ourselves to comets with first-class orbits, the change of $1 / a_{\text {ori }}$ due to incorporating the NG effects causes one of eight comets to be situated exactly on the border line of Oort spike area.

All comets with second-class orbits are significantly shifted towards higher values of $1 / a_{\text {ori }}$, that is, considerably smaller semi-major axes. However, the uncertainties of the derived $1 / a_{\text {ori }}$ are very large and preclude any conclusion, except for the conclusion that three second-class objects do not seem to be Oort spike comets. According to the solutions listed in MW08, only two of them (C/1914 F1 and C/1937 N1) are slightly beyond the right border of the Oort spike region (two dark steel-blue points on the right side of Fig. 5). It is interesting to note that our GR solutions yield $1 / a_{\text {ori }}$ well inside the Oort spike for both these comets (two dark red points in the middle of the figure).

Only one comet, C/1942 C2 (orbit of first class), in the investigated sample has a hyperbolic barycentric original orbit of $1 / a_{\text {ori }}=(-29.1 \pm 13.5) \times 10^{-6} \mathrm{AU}^{-1}$ (upper panel of Fig. 4). This comet has a perihelion distance larger than $4 \mathrm{AU}$, and we were only able to determine a GR solution. At the level of 3 sigma, this comet does not have to be a stranger coming from the interstellar space, but it could be a comet of the solar 


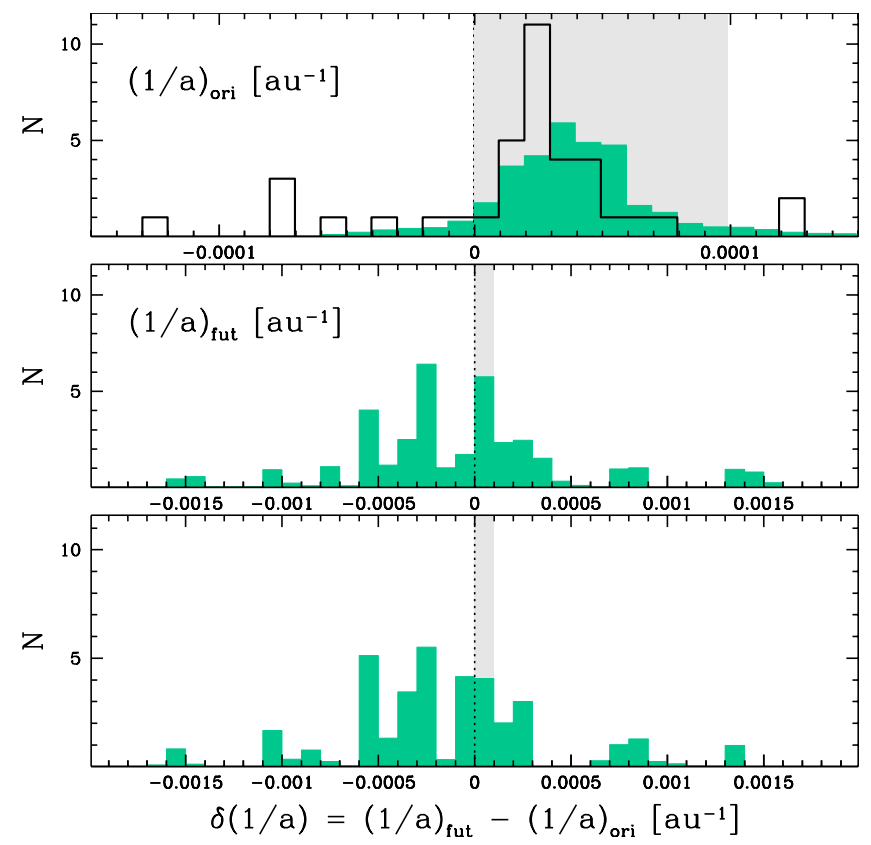

Fig. 7. Distribution of $1 / a_{\mathrm{ori}}$ (top panel), $1 / a_{\mathrm{fut}}$ (middle panels) and $\delta(1 / a)$ for considered LPCs. The black histogram given in the top panel represents the distribution taken from MW08. The uncertainties of our $1 / a$-determinations were incorporated in these $1 / a$-histograms by taking the full cloud of VCs for each comet. Two comets are outside the right border in the upper plot: C/1914 F1 $\left(1 / a_{\text {ori }}=600 \pm 153\right.$, orbit of $2 \mathrm{~b}$ class $)$ and $\mathrm{C} / 1937 \mathrm{~N} 1\left(1 / a_{\text {ori }}=507 \pm 101\right.$, 2a class $)$, both with NG orbits.

system. This comet also has a formally negative value of $1 / a_{\text {ori }}=$ $-34 \times 10^{-6} \mathrm{AU}^{-1}$ in MW08, very close to our value. Of the seven more comets with negative $1 / a_{\text {ori }}$ in MW08, only three have orbits of second class (in MW08), and one more case of $1 / a_{\text {ori }}$ is marginally negative. Four of these hyperbolic comets in MW08 (C/1906 B1, C/1911 S3, C/1946 C1 and C/1946 U1) have determinable NG effects according to our investigations with elliptic original orbits, as shown in the middle panel of Fig. 6 . The remaining three have positive $1 / a_{\text {ori }}$ in our GR model of motion (C/1904 Y1, C/1932 M1, and C/1940 S1, see Table C.1).

Figure 6 shows the $1 / a_{\text {ori }}$-shifts caused by incorporating the $\mathrm{NG}$ effects in the model of motion. The five largest $1 / a_{\text {ori }}$-shifts are observed for comets of second-class orbits. However, the uncertainties of the $1 / a_{\text {ori }}$ determination are also large in all these cases. The goodness of NG model fit to the positional data compared to the GR model is discussed in detail in Sect. 4.1.1 for all

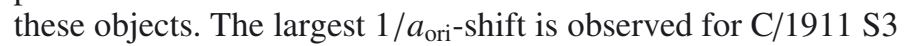
(far outside the right border of Fig. 6), where a pure GR solution gives a hyperbolic original orbit both in the present investigation and in MW08.

The distributions of $1 / a_{\text {ori }}$ and $1 / a_{\text {fut }}$ are presented in Fig. 7 in the upper and middle panels. The middle panel and Table C.1 show that 19 comets $(50 \%)$ are escaping from the solar system on hyperbolic orbits, and one more, C/1914 M1, has a marginally bound future barycentric orbit.

In the upper panel of Fig. 7 we compare our results for the best models of motion (turquoise distribution) with those taken from MW08 (black histogram). The difference between distributions of $1 / a_{\text {ori }}$ is striking. The distribution resulting from our investigation is wider and shifted towards higher values of $1 / a_{\text {ori }}$. This difference results from $1 / a_{\text {ori-shifts caused by NG effects }}$ derived for 13 comets ( $1 / 3$ of the sample) and because uncertainties of $1 / a_{\text {ori }}$ were incorporated in our distribution. For

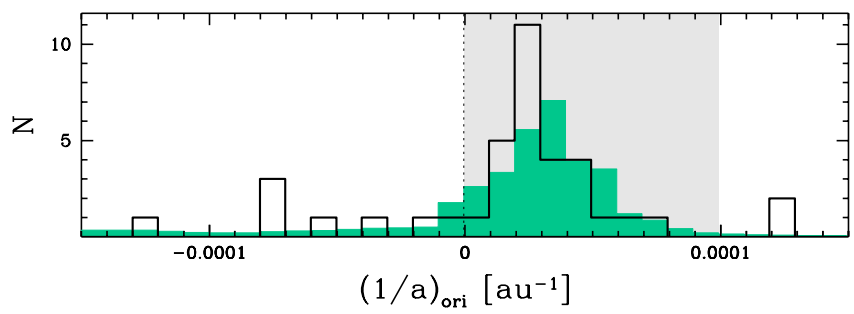

Fig. 8. Same as in the top panel of Fig. 7 when only pure GR solutions are taken into consideration.

comparison, Fig. 8 displays the $1 / a_{\text {ori }}$-distribution for our GR solutions alone. Thus, both plots are based on 38 swarms $\times 5001=$ 190038 VCs, where each swarm of 5001 VCs fits to the respective data set well.

The largest uncertainties of $1 / a_{\text {ori }}$ (larger than 50 in units of $10^{-6} \mathrm{AU}^{-1}$ ) belong to comets $\mathrm{C} / 1940 \mathrm{~S} 1$ Okabayashi-Honda $\left(1 / a_{\text {ori }}=297 \pm 427, \mathrm{NG}\right.$ orbit of $2 \mathrm{~b}$ class $), \mathrm{C} / 1911 \mathrm{~S} 3$ Beljawsky $\left(1 / a_{\text {ori }}=796 \pm 205\right), \mathrm{NG}$ orbit, $2 \mathrm{~b}$ class $), \mathrm{C} / 1914 \mathrm{~F} 1$ Kritzinger $\left(1 / a_{\text {ori }}=600 \pm 153, \mathrm{NG}\right.$ orbit, $2 \mathrm{~b}$ class $), \mathrm{C} / 1904 \mathrm{Y} 1$ Giacobini ( $1 / a_{\text {ori }}=101 \pm 117$, GR orbit, $2 \mathrm{~b}$ class $), \mathrm{C} / 1937 \mathrm{~N} 1$ Finsler $\left(1 / a_{\text {ori }}=507 \pm 101, \mathrm{NG}\right.$ orbit, $2 \mathrm{a}$ class $), \mathrm{C} / 1921 \mathrm{E} 1$ Reid ( $1 / a_{\text {ori }}=85.9 \pm 80.8$, NG orbit, 2a class), and C/1919 Q2 Metcalf $\left(1 / a_{\text {ori }}=34.7 \pm 67.3\right.$, GR orbit, 2 a class $)$; see also Figs. 4 and 6. The first, C/1940 S1, forms an almost constant and negligible background for the $1 /$ a-distribution. The next three comets $(\mathrm{C} / 1911 \mathrm{~S} 3, \mathrm{C} / 1914 \mathrm{~F} 1$ and C/1937 N1) have $1 / a_{\text {ori }}$ formally far outside the right border of the Oort spike, within $3-4 \sigma$ error barely reaching the right side of the Oort spike, and practically do not contribute to the Oort spike distribution either. The distribution of $1 / a_{\text {ori }}$ of the remaining three comets (C/1904 Y1, C/1921 E1 and C/1919 Q2) are scattered throughout the entire Oort spike according to their individual $1 / a$-Gaussians. Almost all remaining investigated comets have uncertainties of their $1 / a_{\text {ori }}$ comparable to the width of a single bin in Fig. 7. Thus, it is obvious that $1 / a_{\text {ori }}$-errors should be taken into account for Oort spike construction, as was done in Figs. 7, 8 .

The shape of Oort spike distribution based on 157 nearparabolic comets is presented in the upper panel of Fig. 9, where 119 comets analysed by Królikowska (2014) were included. The maximum of $1 / a_{\text {ori }}$ is broad and extends between 0.000010 and $0.000065 \mathrm{AU}^{-1}$. This $1 / a_{\text {ori }}$-distribution seems to have a local minimum somewhere between 0.000025 and $0.000035 \mathrm{AU}^{-1}$ (spans over at least two bins). It is important to stress here that histograms based on twice wider bins give different shapes depending on how we distributed these wider bins (zero point in the middle of the bin or on its edge).

The lower panel of Fig. 9 shows the distribution of the future reciprocals of semi-major axes. About $50 \%$ of these comets leave the solar system on hyperbolic, barycentric orbits, and $13 \%$ of the future semi-major axes are still inside the Oort spike. Recent simulations performed by Fouchard et al. (2013) give very similar values, although a little lower. The narrow peak in the range $\left|1 / a_{\text {fut }}\right|<0.000100 \mathrm{AU}^{-1}$ is striking and includes about $30 \%$ of the entire sample. This means that a significant number of these actual comets suffers small planetary perturbations during the passage through the planetary zone.

\section{Summary}

The four main features that distinguish this catalogue of orbits of one-apparition comets discovered in the early twentieth century 

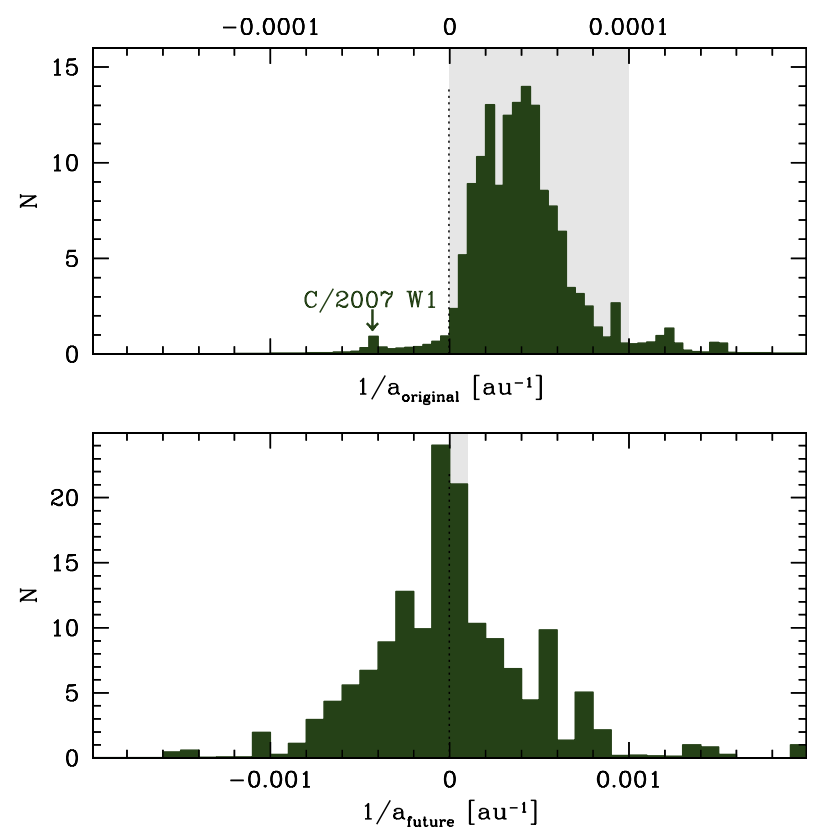

Fig. 9. Same as in the top and middle panels of Fig. 7, but including 119 comets taken from Królikowska (2014). Both distributions are composed of 157 individual normalized $1 / a$-distributions, each resulting from the dynamical calculations of $5001 \mathrm{VCs}$.

from other catalogues of orbits of similarly old objects are the following:

1. Old cometary positional observations require very careful analysis. For the purpose of this new catalogue, great emphasis has been placed on collecting sets of observations as complete as possible for the investigated comets. Moreover, for many observations comet-minus-star measurements were also available. This type of data was particularly valuable as the most original measurement of comet positions and has allowed us to recalculate new positions of comets using the PPM star catalogue.

2. Old cometary observations were prepared by observers usually as apparent positions in right ascension and declination or as reduced positions for the epoch of the beginning of the year of a given observation. This was a huge advantage of these data, because it allowed us to uniformly take into account all necessary corrections associated with the data reduction to the standard epoch.

3. Osculating orbits of one-apparition comets discovered more than sixty years ago have formerly been determined with very different numerical methods and assumptions on the model of the solar system, including the number of planets taken into account. This new catalogue changes this situation. We offer a new catalogue of cometary orbits derived using completely homogeneous methods of data treatment, accurate methods of numerical integration, and a modern solar system model.
4. The osculating, original, and future sets of orbits are presented for each catalogue comet. For a comet with detectable NG effects, we give both types of orbit: purely gravitational and non-gravitational. We conclude, however, that all thirteen NG orbital solutions given in the catalogue better represent the actual motions of the investigated comets. Surprisingly, NG effects were detectable in data for five comets of second-class orbits. Among these five are three comets (C/1906 B1, C/1911 S3, C/1921 E1) with hyperbolic original, barycentric GR orbits.

Acknowledgements. This publication is dedicated to the memory of Maciej Bielicki (1906-1988), one of the initiators of this catalogue of one-apparition comets. The orbits were calculated using the numerical orbital package developed by Grzegorz Sitarski and the Solar System Dynamics and Planetology Group at SRC PAS. Special thanks to everyone who, many years ago, participated in the data collection from the literature and in the very preliminary analysis of these observations, among others, Wanda Borodziewicz and Tomasz Chlebowski.

\section{References}

Bielicki, M. 1972, in The Motion, Evolution of Orbits, and Origin of Comets, eds. G. A. Chebotarev, E. I. Kazimirchak-Polonskaia, \& B. G. Marsden, IAU Symp., 45, 112

Bielicki, M., \& Sitarski, G. 1991, Acta Astron., 41, 309

Bielicki, M., \& Ziołkowski, K. 1976, Acta Astron., 26, 371

Fouchard, M., Rickman, H., Froeschlé, Ch., \& Valsecchi, G. B. 2013, Icarus, 222,20

Gabryszewski, R. 1997, P\&SS, 45, 1653

Grubissich, C. 1952, Mem. Soc. Astron. It., 22, 251

IAU Minor Planet Center, 2013, MPC Database Search, URL http://www.minorplanetcenter.net/db_search/

Królikowska, M. 2001, A\&A, 376, 316

Królikowska, M. 2004, A\&A, 427, 1117

Królikowska, M. 2006, Acta Astron., 56, 385

Królikowska, M. 2014, A\&A, 567, A126

Królikowska, M., \& Dybczyński, P. A. 2010, MNRAS, 404, 1886

Królikowska, M., \& Dybczyński, P. A. 2013, MNRAS, 435, 440

Królikowska, M., Sitarski, G., \& Sołtan, A. M. 2009, MNRAS, 399, 1964

Kronk, G. W. 2008, Cometography. A Catalog of Comets, 3, 1900

Marsden, B. G., \& Williams, G. V. 2008, Catalogue of Cometary Orbits 17th Ed. (Cambridge, Mass.: Smithsonian Astrophysical Observatory)

Marsden, B. G., Sekanina, Z., \& Yeomans, D. K. 1973, AJ, 78, 211

Marsden, B. G., Sekanina, Z., \& Everhart, E. 1978, AJ, 83, 64

Rickman, H., Sitarski, G., \& Todorovic-Juchniewicz, B. 1987, A\&A, 188, 206

Sitarski, G. 1972, in The Motion, Evolution of Orbits, and Origin of Comets, eds. G. A. Chebotarev, E. I. Kazimirchak-Polonskaia, \& B. G. Marsden, IAU Symp., 45, 107

Sitarski, G. 1979a, in Dynamics of the Solar System (Dordrecht: D. Reidel Publishing Co), IAU Symp., 81, 289

Sitarski, G. 1979b, Acta Astron., 29, 401

Sitarski, G. 1984, Acta Astron., 34, 53

Sitarski, G. 1989, Acta Astron., 39, 345

Sitarski, G. 1992, AJ, 104, 1226

Sitarski, G. 1994, Acta Astron., 44, 91

Sitarski, G. 1998, Acta Astron., 48, 547

Sitarski, G. 2002, Acta Astron., 52, 471

Standish, E. M. 1998, JPL Planetary and Lunar Ephemerides, DE405/LE405, Tech. Rep. IOM 312.F-98-048

Todorovic-Juchniewicz, B. 1981, Acta Astron., 31, 192

Williams, G. V. 2005, Minor Planet Circulars, 54698, 6

Yeomans, D. K., \& Chodas, P. W. 1989, AJ, 98, 1083 


\section{Appendix A: Collected observational data and data processing}

Table A.1. Collected observational material for the sample of 38 LPCs discovered during 1901-1950 (Cols. (4)-(7)).

\begin{tabular}{|c|c|c|c|c|c|c|c|c|}
\hline \multirow[b]{2}{*}{$\begin{array}{l}\text { Comet } \\
\text { name }\end{array}$} & \multirow[b]{2}{*}{$\begin{array}{l}q_{\mathrm{osc}} \\
{[\mathrm{AU}]} \\
(2)\end{array}$} & \multirow[b]{2}{*}{$T$} & \multicolumn{4}{|c|}{ Observational material } & \multicolumn{2}{|l|}{$\mathrm{MW} 08$} \\
\hline & & & $\begin{array}{l}\text { Observational arc } \\
\text { dates } \\
\text { [yyyymmdd-yyyymmdd] } \\
\text { (4) }\end{array}$ & $\begin{array}{r}\text { No. } \\
\text { of } \\
\text { obs } \\
(5)\end{array}$ & $\begin{array}{l}\text { Data } \\
\text { arc span } \\
\text { [yr] } \\
(6)\end{array}$ & $\begin{array}{l}\text { Heliocentric } \\
\text { distance span } \\
\text { [AU] } \\
\text { (7) }\end{array}$ & $\begin{array}{c}\text { Observational arc } \\
\text { dates } \\
\text { [yyyymmdd-yyyymmdd] } \\
\text { (8) }\end{array}$ & $\begin{array}{r}\text { No. } \\
\text { of } \\
\text { obs } \\
(9)\end{array}$ \\
\hline C/1902 R1 & 0.401 & 19021124 & $19020901-19030331$ & 1491 & 0.58 & $1.79-2.44$ & 19020901-19030331 & 1000 \\
\hline C/1902 X1 & 2.77 & 19030323 & 19021202-19030627 & 735 & 0.57 & $3.00-2.94$ & 19021204-19030624 & 191 \\
\hline C/1903 M1 & 0.330 & 19030828 & 19030629-19031023 & 653 & 0.36 & $1.52-1.36$ & 19030622-19031023 & 231 \\
\hline C/1904 Y1 & 1.88 & 19041103 & 19041218-19050502 post & 164 & 0.37 & $1.96-2.86$ & 19041218-19050502 & 48 \\
\hline C/1906 B1 & 1.30 & 19051222 & 19050723-19060425 post+ & 267 & 0.76 & $2.50-2.18$ & 19050723-19060424 & $186^{*}$ \\
\hline C/1906 E1 & 3.35 & 19051018 & 19040110-19070704** post + & 462 & 3.48 & $6.53-6.38$ & 19040110-19070704 & 500 \\
\hline C/1907 E1 & 2.05 & 19070319 & 19070309-19080226 & 178 & 0.97 & $2.05-4.29$ & 19070309-19080226 & 67 \\
\hline C/1911 S3 & 0.303 & 19111010 & $19110929-19120217^{1}$ & 162 & 0.38 & $0.46-2.55$ & 19110930-19120217 & 66 \\
\hline C/1912 R1 & 0.716 & 19121005 & $19120911-19130526^{2}$ & 935 & 0.71 & $0.86-3.59$ & 19120910-19130526 & 170 \\
\hline C/1913 Y1 & 1.10 & 19141026 & $19131218-19150907^{3}$ & 1006 & 1.72 & $4.24-4.26$ & $19131218-19150907$ & 339 \\
\hline C/1914 F1 & 1.20 & 19140604 & 19140330-19141214 & 285 & 0.48 & $1.57-2.94$ & 19140330-19141214 & 62 \\
\hline C/1914 M1 & 3.75 & 19140730 & $19140624-19150810^{4}$ & 70 & 1.13 & .96 & 150715 & 39 \\
\hline C/1916 G1 & 1.69 & 19170617 & 19160407-19180129 & 471 & 1.81 & $5.16-5.74$ & 19160404-19180129 & 186 \\
\hline C/1919 Q2 & 1.12 & 19191207 & 19190825-19200203 & 276 & 0.44 & $1.95-1.75$ & 19190825-19200203 & 87 \\
\hline C/1921 E1 & 1.01 & 19210510 & 19210315-19211126 & 568 & 0.70 & $1.74-2.25$ & 19210315-19211126 & 146 \\
\hline C/1922 U1 & 2.26 & 19221026 & 19221022-19240128 post+ & 482 & 1.27 & $2.26-5.22$ & 19221022-19240128 & 185 \\
\hline C/1925 F1 & 4.18 & 19250906 & $19250323-19270304^{5}$ & 262 & 1.95 & $4.41-6.07$ & 19250323-19270304 & 59 \\
\hline C/1925 G1 & 1.11 & 19250401 & $19250405-19260502^{6}$ post & 598 & 1.07 & $1.11-5.15$ & 19250405-19260502 & 201 \\
\hline C/1925 W1 & 1.57 & 19251002 & $19251117-19260610^{7}$ post & 342 & 0.56 & $1.57-3.47$ & 19251117-19260531 & 129 \\
\hline C/1932 M1 & 1.65 & 19320924 & $19320621-19330120^{8}$ & 187 & 0.58 & $2.06-2.25$ & 19320621-19321230 & 48 \\
\hline C/1932 M2 & 2.31 & 820721 & 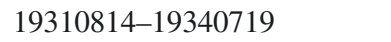 & 328 & 2.93 & & 19310814-19340719 & 161 \\
\hline C/1935 Q1 & 4.04 & 19360511 & $19350703-19371112^{9}$ & 131 & 2.30 & $4.83-6.06$ & 19350703-19371110 & 107 \\
\hline $\mathrm{C} / 1937 \mathrm{C} 1$ & 1.73 & 19370620 & 19370204-19371028 & 417 & 0.72 & $2.44-2.40$ & 19370204-19371028 & 136 \\
\hline C/1937 N1 & 0.863 & 19370815 & 19370704-19371230 & 413 & 0.49 & $1.14-2.36$ & 19370704-19371230 & 212 \\
\hline C/1940 R2 & 0.368 & 19410116 & $19400825-19410401^{* * *}$ & 370 & & $2.71-1.67$ & 19400919-19410617 & 189 \\
\hline C/1940 S1 & 1.06 & 19400815 & $19401004-19410103^{10}$ post & 36 & 0.25 & $1.34-2.37$ & 19401004-19410102 & 19 \\
\hline C/1941 K1 & 0.875 & 19410903 & 19410604-19420218 & 461 & 0.71 & $1.76-2.74$ & 19410604-19420218 & 318 \\
\hline C/1942 C1 & 1.44 & 19420430 & 19411228-19430108 & 224 & 1.03 & $2.22-3.51$ & 19411228-19430108 & 228 \\
\hline C/1942 C2 & 4.11 & 19420927 & $19420212-19430311^{11}$ & 47 & 1.07 & $4.53-4.35$ & 19420212-19430309 & 35 \\
\hline C/1944 K2 & 2.23 & 19440717 & 19440601-19450811 & 36 & 1.19 & $2.29-4.66$ & 19440601-19450811 & 25 \\
\hline C/1946 C1 & 1.72 & 19460413 & $19460129-19470809^{12}$ & 485 & 1.52 & $1.97-5.56$ & 19460202-19470809 & 183 \\
\hline C/1946 P1 & 1.14 & 19461026 & $19460813-19481123^{13}$ & 144 & 2.28 & $1.62-8.17$ & 19460816-19481123 & 101 \\
\hline C/1946 U1 & 2.41 & 19470207 & 19461102-19481002 & 141 & 1.92 & $2.64-6.32$ & 19461102-19481002 & 97 \\
\hline
\end{tabular}

Notes. The sample includes all comets that in MW08 have $1 / a_{\text {ori }}<130 \times 10^{-6} \mathrm{AU}^{-1}$ and orbits of first- or second-class. Columns (2)-(4) show the osculating perihelion distance, perihelion time, and interval of collected data. The data distribution relative to perihelion passage is shown by additional descriptions: "post" in Col. (4) when all observations were taken after perihelion passage, and "post+" when the number of data taken after perihelion passage dominate. Columns (8)-(9) describe the positional data that formed the basis for determining the orbits presented in MW08. Comets with detectable NG effects are indicated here by rows in light grey shading (see also Table C.1). Notes to cases where we found in literature observations outside the data interval given in MW08 (in Col. (8) of this table): ${ }^{(1)}$ One observation of poor quality was taken on 1911 September 29. Although a hundred times less weight in comparison to good-quality observations was applied, this measurement was rejected in the selecting and weighting. ${ }^{(2)}$ One observation was taken on 1912 May 09, two in 1912 September 09, but all three were rejected as incorrect; a single observation from 1912 September 10 was also rejected. ${ }^{(3)}$ Three observations taken on 1913 October 25, 26, and 31 are outliers. (4) One observation taken on 1914 June 24 (well fitted in right ascension and declination) and two observations taken on 1915 August 10 (only in declination) were also used here to determine the orbit. ${ }^{(5)}$ Two observations were taken on 1925 March 22, but were rejected as outliers. ${ }^{(6)}$ One observation was taken on 1925 April 05 and was included in the orbit determination only in right ascension. ${ }^{(7)}$ Two observations were taken on 1926 June 09 and 10 and were included in the orbit determination only in right ascension and declination, respectively. ${ }^{(8)}$ One observation taken on 1933 January 20 was included in the orbit determination in declination. ${ }^{(9)}$ One observation taken on 1937 November 12 was included in declination in the orbit determination. ${ }^{(10)}$ Three observations were taken on 1941 January 03 - these were included in the orbit determination only in right ascension. ${ }^{(1)}$ Two observations were taken on 1943 March 11 and were included. (12) One observation taken on 1946 January 29 was included. ${ }^{(13)}$ Two observations were taken on 1946 August 13; the first was included only in declination, and the second in both coordinates. Other notes $^{(*)}$ This is the unique case where a large set of observations is available at IAU Minor Planet Center Database. There are 239 positional observations, two of which are prediscovery observations found by Gary W. Kronk; they extend the data interval by about six months (see also Sect. 2). ${ }^{(* *)}$ Before perihelion only two observations were taken on 1904 January 10 and 1905 January $15 .^{(* * *)}$ Our data interval is significantly shorter than in MW08. Data after 1941 April 01 are needed. 
Table A.1. continued.

\begin{tabular}{|c|c|c|c|c|c|c|c|c|}
\hline \multirow[b]{2}{*}{$\begin{array}{l}\text { Comet } \\
\text { name } \\
\text { (1) }\end{array}$} & \multirow[b]{2}{*}{$\begin{array}{l}q_{\mathrm{osc}} \\
{[\mathrm{AU}]} \\
(2)\end{array}$} & \multirow[b]{2}{*}{$\begin{array}{c}T \\
\text { [yyyymmdd] } \\
\text { (3) }\end{array}$} & \multicolumn{4}{|c|}{ Observational material } & \multirow{2}{*}{$\begin{array}{c}\text { M W } 08 \\
\text { Observational arc } \\
\text { dates } \\
\text { [yyyymmdd-yyyymmdd] } \\
(8)\end{array}$} & \multirow[b]{2}{*}{$\begin{array}{r}\text { No } \\
\text { of } \\
\text { obs } \\
(9)\end{array}$} \\
\hline & & & $\begin{array}{l}\text { Observational arc } \\
\text { dates } \\
\text { [yyyymmdd-yyyymmdd] } \\
\text { (4) }\end{array}$ & $\begin{array}{r}\text { No } \\
\text { of } \\
\text { obs } \\
(5)\end{array}$ & $\begin{array}{l}\text { Data } \\
\text { arc span } \\
\text { [yr] } \\
(6)\end{array}$ & $\begin{array}{l}\text { Heliocentric } \\
\text { distance span } \\
\text { [AU] } \\
\text { (7) }\end{array}$ & & \\
\hline $\mathrm{C} / 1947 \mathrm{~S} 1$ & 0.748 & 19480216 & $19470928-19490206$ & 325 & 1.36 & $2.45-4.89$ & $19470928-19490206$ & 123 \\
\hline C/1947 Y1 & 1.50 & 19480216 & $19480118-19481130$ & 124 & 0.87 & $1.59-3.85$ & $19480118-19481130$ & 78 \\
\hline C/1948 E1 & 2.11 & 19480515 & 19480313-19500209 & 247 & 1.91 & $2.36-6.65$ & 19480313-19500209 & 95 \\
\hline $\mathrm{C} / 1948 \mathrm{~T} 1$ & 3.26 & 19470904 & $19481007-19500817$ post & 26 & 1.86 & $4.89-9.38$ & 19481007-19500817 & 26 \\
\hline $\mathrm{C} / 1950 \mathrm{~K} 1$ & 2.57 & 19510115 & 19500527-19530119 & 254 & 2.65 & $3.53-7.26$ & 19500527-19530119 & 38 \\
\hline
\end{tabular}

Table A.2. Collected ( $\downarrow$ - $)$ observations ((comet-star) positions in right ascension and declination).

\begin{tabular}{|c|c|c|c|c|c|c|c|}
\hline \multirow{2}{*}{$\begin{array}{l}\text { Comet } \\
\text { (1) }\end{array}$} & \multirow{2}{*}{$\begin{array}{r}\text { Number of } \\
\tau-\star \\
\text { obs. } \\
(2)\end{array}$} & \multirow{2}{*}{$\begin{array}{r}\text { Number of } \\
\text { recalculated } \\
\checkmark \text { positions } \\
(3)\end{array}$} & \multirow{2}{*}{$\begin{array}{c}\text { Per cent of } \\
\text { recalculated } \\
\text { observations } \\
\text { (4) }\end{array}$} & \multicolumn{3}{|c|}{$\begin{array}{l}\text { Preliminary gravitational } \\
\text { before PPM }\end{array}$} & \multirow{2}{*}{$\begin{array}{l}\text { s o } 1 \text { u t i o n } \\
\text { PPM } \\
\text { of residuals } \\
\text { (8) }\end{array}$} \\
\hline & & & & $\underset{(5)}{\operatorname{rms}\left[{ }^{\prime \prime}\right]}$ & $\begin{array}{l}\text { No. of residuals } \\
\text { (6) }\end{array}$ & $\begin{array}{c}\operatorname{rms}\left[{ }^{\prime} \cdot\right] \\
(7)\end{array}$ & \\
\hline C/1902 R1 & 1175 & 753 & 51 & 3.76 & 2454 & 3.53 & 2472 \\
\hline C/1902 X1 & 606 & 436 & 59 & 3.48 & 1290 & 3.37 & 1301 \\
\hline C/1903 M1 & 430 & 379 & 65 & 4.39 & 920 & 3.76 & 920 \\
\hline C/1904 Y1 & 150 & 132 & 80 & 3.32 & 300 & 3.26 & 301 \\
\hline C/1906 B1 & 226 & 135 & 51 & 4.45 & 456 & 3.77 & 450 \\
\hline C/1906 E1 & 369 & 315 & 68 & 2.45 & 775 & 2.58 & 806 \\
\hline C/1907 E1 & 157 & 129 & 72 & 4.14 & 304 & 2.82 & 292 \\
\hline C/1911 S3 & 137 & 86 & 63 & 3.83 & 243 & 3.27 & 261 \\
\hline C/1912 R1 & 864 & 726 & 77 & 3.84 & 1635 & 2.91 & 1646 \\
\hline C/1913 Y1 & 947 & 788 & 78 & 3.33 & 1773 & 2.70 & 1798 \\
\hline C/1914 F1 & 266 & 229 & 92 & 4.10 & 496 & 3.88 & 500 \\
\hline C/1914 M1 & 47 & 29 & 41 & 2.83 & 122 & 2.41 & 118 \\
\hline C/1916 G1 & 375 & 291 & 62 & 3.49 & 760 & 3.14 & $8364^{\top}$ \\
\hline C/1919 Q2 & 247 & 208 & 75 & 3.38 & 488 & 2.58 & 498 \\
\hline C/1921 E1 & 498 & 392 & 69 & 4.64 & 827 & 4.49 & $9 1 6 \longdiv { 7 }$ \\
\hline C/1922 U1 & 409 & 276 & 57 & 2.62 & 738 & 2.57 & $823 \overbrace{}^{\top}$ \\
\hline $\mathrm{C} / 1925 \mathrm{~F} 1$ & 193 & 157 & 59 & 4.48 & 449 & 4.34 & 472 \\
\hline $\mathrm{C} / 1925 \mathrm{G} 1$ & 409 & 366 & 61 & 4.89 & 946 & 4.71 & 968 \\
\hline C/1925 W1 & 246 & 201 & 59 & 2.92 & 541 & 2.39 & 564 \\
\hline C/1932 M1 & 111 & 90 & 48 & 3.52 & 314 & 2.89 & 316 \\
\hline C/1932 M2 & 165 & 96 & 29 & 2.13 & 521 & 2.13 & 536 \\
\hline C/1935 Q1 & 16 & 4 & 3 & 1.63 & 248 & 1.62 & 248 \\
\hline $\mathrm{C} / 1937 \mathrm{C} 1$ & 220 & 187 & 45 & 4.42 & 745 & 3.49 & 729 \\
\hline C/1937 N1 & 170 & 153 & 37 & 3.69 & 733 & 3.01 & 745 \\
\hline C/1940 R2 & 127 & 113 & 31 & 2.33 & 612 & 2.19 & 605 \\
\hline C/1940 S1 & 5 & 2 & 6 & 5.11 & 65 & 5.10 & 65 \\
\hline C/1941 K1 & 111 & 93 & 20 & 3.09 & 769 & 3.26 & 778 \\
\hline C/1942 C1 & 39 & 38 & 17 & 2.41 & 414 & 2.41 & 414 \\
\hline C/1942 C2 & 0 & 0 & 0 & 1.65 & 88 & 1.65 & 88 \\
\hline C/1944 K2 & 0 & 0 & 0 & 1.58 & 56 & 1.58 & 56 \\
\hline C/1946 C1 & 78 & 54 & 11 & 2.71 & 828 & 2.71 & 828 \\
\hline C/1946 P1 & 8 & 5 & 3 & 1.13 & 254 & 1.13 & 254 \\
\hline C/1946 U1 & 33 & 20 & 14 & 1.88 & 252 & 1.88 & 254 \\
\hline C/1947 S1 & 64 & 59 & 18 & 4.62 & 551 & 4.32 & 553 \\
\hline C/1947 Y1 & 4 & 4 & 3 & 1.44 & 198 & 1.44 & 198 \\
\hline C/1948 E1 & 26 & 23 & 9 & 2.44 & 400 & 2.31 & 401 \\
\hline $\mathrm{C} / 1948 \mathrm{~T} 1$ & 0 & 0 & 0 & 0.94 & 52 & 0.94 & 52 \\
\hline C/1950 K1 & 0 & 0 & 0 & 1.28 & 466 & 1.28 & 466 \\
\hline
\end{tabular}

Notes. Column (3) shows the number of recalculated $\left(\boldsymbol{\tau}^{-} \star\right.$ ) positions using the PPM catalogue, their percentage in comparison to the entire data set collected here (see Col. (5) of Table A.1) is given in Col. (4). The rms and number of residuals taken for preliminary solution are given in Cols. (5)-(6) - before position recalculations based on PPM catalogue, and in Cols. (7)-(8) - after this recalculation. In some cases only ( $\downarrow$ - $\star$ ) data were published - where a significant number of these observations were successfully processed using the PPM star catalogue are marked by $\tau^{\top}$ in Col. (8). 


\section{Appendix B: Osculating orbital elements (heliocentric)}

Table B.1. Orbital elements of osculating heliocentric orbits for all models described in Table C.1.

\begin{tabular}{|c|c|c|c|c|c|c|c|c|}
\hline Comet & $\begin{array}{c}\text { Epoch } \\
\text { [yyyymmdd] } \\
(2)\end{array}$ & $\begin{array}{r}T \\
\text { [yyyymmdd.dddddd] } \\
(3) \\
\end{array}$ & $\begin{array}{r}q \\
{[\mathrm{AU}]} \\
(4) \\
\end{array}$ & (5) & $\begin{array}{r}\omega \\
{\left[^{\circ}\right]} \\
(6) \\
\end{array}$ & $\begin{array}{r}\Omega \\
{\left[{ }^{\circ}\right]} \\
(7) \\
\end{array}$ & $\begin{array}{r}i \\
{\left[{ }^{\circ}\right]} \\
(8) \\
\end{array}$ & $\begin{array}{r}1 / a_{\text {osc }} \\
{\left[10^{-6} \mathrm{AU}^{-1}\right]} \\
(9) \\
\end{array}$ \\
\hline C/1902 R1 & 19021127 & $\begin{array}{r}19021124.356684 \\
\pm .000025\end{array}$ & $\begin{array}{l}0.40107241 \\
\pm .00000033\end{array}$ & $\begin{array}{l}0.99996675 \\
\pm .00000068\end{array}$ & $\begin{array}{r}152.983569 \\
\pm .000085\end{array}$ & $\begin{array}{r}50.740193 \\
\pm .000087\end{array}$ & $\begin{array}{r}156.354721 \\
\pm .000036\end{array}$ & $\begin{array}{r}82.897510 \\
\pm 1.714706\end{array}$ \\
\hline C/1902 X1 & 19030327 & $\begin{array}{r}19030323.974159 \\
\pm .002541\end{array}$ & $\begin{array}{r}2.77348499 \\
\pm .00001328\end{array}$ & $\begin{array}{r}1.00047034 \\
\pm .00001976\end{array}$ & $\begin{array}{l}5.830937 \\
\pm .000781\end{array}$ & $\begin{array}{r}118.810872 \\
\pm .000085\end{array}$ & $\begin{array}{r}43.894598 \\
\pm .000258\end{array}$ & $\begin{array}{r}-169.586058 \\
\pm 7.124391\end{array}$ \\
\hline C/1903 M1 & 19030903 & $\begin{array}{r}19030828.108377 \\
\pm .000058\end{array}$ & $\begin{array}{r}0.33018087 \\
\pm .00000150\end{array}$ & $\begin{array}{r}1.00040917 \\
\pm .00000310\end{array}$ & $\begin{array}{r}127.251980 \\
\pm .000260\end{array}$ & $\begin{array}{r}294.909653 \\
\pm .000054\end{array}$ & $\begin{array}{r}85.015231 \\
\pm .000197\end{array}$ & $\begin{array}{r}-1239.232832 \\
\pm 9.400340\end{array}$ \\
\hline C/1904 Y1 & 19041116 & $\begin{array}{r}19041103.774111 \\
\pm .013312\end{array}$ & $\begin{array}{r}1.88176420 \\
\pm .00010009\end{array}$ & $\begin{array}{r}1.00034373 \\
\pm .00022266\end{array}$ & $\begin{array}{r}40.723034 \\
\pm .006760\end{array}$ & $\begin{array}{r}219.786197 \\
\pm .000583\end{array}$ & $\begin{array}{r}99.600058 \\
\pm .000577\end{array}$ & $\begin{array}{l}-182.662119 \\
\pm 118.316762\end{array}$ \\
\hline C/1906 B1 & 19051221 & $\begin{array}{r}19051222.834099 \\
\pm .000635\end{array}$ & $\begin{array}{r}1.29656822 \\
\pm .00000329\end{array}$ & $\begin{array}{r}1.00118940 \\
\pm .00002875\end{array}$ & $\begin{array}{r}89.875094 \\
\pm .000333\end{array}$ & $\begin{array}{r}287.700661 \\
\pm .000299\end{array}$ & $\begin{array}{r}126.443151 \\
\pm .000191\end{array}$ & $\begin{array}{r}-917.341741 \\
\pm 22.172663\end{array}$ \\
\hline & 19051221 & $\begin{array}{r}19051222.827139 \\
\pm .001939\end{array}$ & $\begin{array}{r}1.29649411 \\
\pm .00001882\end{array}$ & $\begin{array}{r}1.00071452 \\
\pm .00012808\end{array}$ & $\begin{array}{r}89.873443 \\
\pm .000523\end{array}$ & $\begin{array}{r}287.702585 \\
\pm .000592\end{array}$ & $\begin{array}{r}126.443226 \\
\pm .000188\end{array}$ & $\begin{array}{r}-551.119344 \\
\pm 98.785605\end{array}$ \\
\hline C/1906 E1 & 19051002 & $\begin{array}{r}19051018.260509 \\
\pm .001894\end{array}$ & $\begin{array}{r}3.33984993 \\
\pm .00001427\end{array}$ & $\begin{array}{r}1.00154602 \\
\pm .00001830\end{array}$ & $\begin{array}{r}158.599798 \\
\pm .000814\end{array}$ & $\begin{array}{r}343.621657 \\
\pm .000729\end{array}$ & $\begin{array}{l}4.282129 \\
\pm .000190\end{array}$ & $\begin{array}{r}-462.902333 \\
\pm 5.480122\end{array}$ \\
\hline C/1907 E1 & 19070309 & $\begin{array}{r}19070319.606941 \\
\pm .001690\end{array}$ & $\begin{array}{r}2.05167901 \\
\pm .00001611\end{array}$ & $\begin{array}{r}1.00099244 \\
\pm .00004395\end{array}$ & $\begin{array}{r}317.118563 \\
\pm .000810\end{array}$ & $\begin{array}{r}98.484125 \\
\pm .000214\end{array}$ & $\begin{array}{r}141.659654 \\
\pm .000193\end{array}$ & $\begin{array}{r}-483.718771 \\
\pm 21.419803\end{array}$ \\
\hline C/1911 S3 & 19111011 & $\begin{array}{r}19111010.764058 \\
\pm .000076\end{array}$ & $\begin{array}{r}0.30342194 \\
\pm .00000078\end{array}$ & $\begin{array}{r}1.00017379 \\
\pm .00001128\end{array}$ & $\begin{array}{r}71.712390 \\
\pm .000390\end{array}$ & $\begin{array}{r}89.896351 \\
\pm .000423\end{array}$ & $\begin{array}{r}96.463409 \\
\pm .000556\end{array}$ & $\begin{array}{r}-572.782721 \\
\pm 37.169996\end{array}$ \\
\hline & 19111011 & $\begin{array}{r}19111010.764561 \\
\pm .000128\end{array}$ & $\begin{array}{r}0.30341412 \\
\pm .00000178\end{array}$ & $\begin{array}{r}0.99988293 \\
\pm .00006089\end{array}$ & $\begin{array}{r}71.714197 \\
\pm .000508\end{array}$ & $\begin{array}{r}89.898109 \\
\pm .000531\end{array}$ & $\begin{array}{r}96.469009 \\
\pm .001332\end{array}$ & $\begin{array}{r}385.827118 \\
\pm 200.696777\end{array}$ \\
\hline C/1912 R1 & 19121005 & $\begin{array}{r}19121005.453192 \\
\pm .000053\end{array}$ & $\begin{array}{r}0.71607473 \\
\pm .00000084\end{array}$ & $\begin{array}{r}1.00045667 \\
\pm .00000377\end{array}$ & $\begin{array}{r}25.621533 \\
\pm .000108\end{array}$ & $\begin{array}{r}298.246936 \\
\pm .000110\end{array}$ & $\begin{array}{r}79.809959 \\
\pm .000085\end{array}$ & $\begin{array}{r}-637.746537 \\
\pm 5.267842\end{array}$ \\
\hline C/1913 Y1 & 19141104 & $\begin{array}{r}19141026.767056 \\
\pm .000062\end{array}$ & $\begin{array}{r}1.10445641 \\
\pm .00000079\end{array}$ & $\begin{array}{r}1.00016199 \\
\pm .00000143\end{array}$ & $\begin{array}{r}97.467346 \\
\pm .000028\end{array}$ & $\begin{array}{r}60.396107 \\
\pm .000024\end{array}$ & $\begin{array}{r}68.038294 \\
\pm .000042\end{array}$ & $\begin{array}{r}-146.670259 \\
\pm 1.291169\end{array}$ \\
\hline & 19141104 & $\begin{array}{r}19141026.767012 \\
\pm .000062\end{array}$ & $\begin{array}{r}1.10444242 \\
\pm .00000218\end{array}$ & $\begin{array}{r}1.00009618 \\
\pm .00000906\end{array}$ & $\begin{array}{r}97.467000 \\
\pm .000059\end{array}$ & $\begin{array}{r}60.396112 \\
\pm .000023\end{array}$ & $\begin{array}{r}68.038602 \\
\pm .000059\end{array}$ & $\begin{array}{r}-87.082819 \\
\pm 8.203185\end{array}$ \\
\hline C/1914 F1 & 19140528 & $\begin{array}{r}19140604.693158 \\
\pm .000256\end{array}$ & $\begin{array}{r}1.19853665 \\
\pm .00000529\end{array}$ & $\begin{array}{r}1.00018867 \\
\pm .00003381\end{array}$ & $\begin{array}{r}72.224168 \\
\pm .000277\end{array}$ & $\begin{array}{r}200.117415 \\
\pm .000322\end{array}$ & $\begin{array}{r}23.914811 \\
\pm .000339\end{array}$ & $\begin{array}{r}-157.414076 \\
\pm 28.212597\end{array}$ \\
\hline & 19140528 & $\begin{array}{r}19140604.695930 \\
\pm .000549\end{array}$ & $\begin{array}{r}1.19844515 \\
\pm .00002359\end{array}$ & $\begin{array}{r}0.99971941 \\
\pm .00012683\end{array}$ & $\begin{array}{r}72.225088 \\
\pm .000443\end{array}$ & $\begin{array}{r}200.114528 \\
\pm .000812\end{array}$ & $\begin{array}{r}23.909795 \\
\pm .001379\end{array}$ & $\begin{array}{r}234.127010 \\
\pm 105.833235\end{array}$ \\
\hline C/1914 M1 & 19140816 & $\begin{array}{r}19140730.491036 \\
\pm .010771\end{array}$ & $\begin{array}{r}3.74680509 \\
\pm .00006838\end{array}$ & $\begin{array}{r}1.00325348 \\
\pm .00009295\end{array}$ & $\begin{array}{r}14.000020 \\
\pm .002102\end{array}$ & $\begin{array}{r}271.513791 \\
\pm .000168\end{array}$ & $\begin{array}{r}71.041017 \\
\pm .000427\end{array}$ & $\begin{array}{r}-868.335053 \\
\pm 24.783913\end{array}$ \\
\hline C/1916 G1 & 19170621 & $\begin{array}{r}19170617.074175 \\
\pm .000244\end{array}$ & $\begin{array}{r}1.68644587 \\
\pm .00000103\end{array}$ & $\begin{array}{r}0.99937443 \\
\pm .00000541\end{array}$ & $\begin{array}{r}120.621838 \\
\pm .000141\end{array}$ & $\begin{array}{r}184.457271 \\
\pm .000054\end{array}$ & $\begin{array}{r}25.659093 \\
\pm .000045\end{array}$ & $\begin{array}{r}370.940610 \\
\pm 3.207311\end{array}$ \\
\hline & 19170621 & $\begin{array}{r}19170617.074377 \\
\pm .000274\end{array}$ & $\begin{array}{r}1.68642132 \\
\pm .00000382\end{array}$ & $\begin{array}{r}0.99932117 \\
\pm .00000954\end{array}$ & $\begin{array}{r}120.621627 \\
\pm .000182\end{array}$ & $\begin{array}{r}184.457166 \\
\pm .000054\end{array}$ & $\begin{array}{r}25.658821 \\
\pm .000063\end{array}$ & $\begin{array}{r}402.529745 \\
\pm 5.658616\end{array}$ \\
\hline C/1919 Q2 & 19191118 & $\begin{array}{r}19191207.809648 \\
\pm .002096\end{array}$ & $\begin{array}{r}1.11527223 \\
\pm .00002732\end{array}$ & $\begin{array}{r}1.00020566 \\
\pm .00007480\end{array}$ & $\begin{array}{r}185.753567 \\
\pm .002470\end{array}$ & $\begin{array}{r}122.098062 \\
\pm .000560\end{array}$ & $\begin{array}{r}46.381870 \\
\pm .000174\end{array}$ & $\begin{array}{r}-184.402616 \\
\pm 67.069931\end{array}$ \\
\hline $\mathrm{C} / 19$ & 19210421 & $\begin{array}{r}19210510.449383 \\
\pm .000308\end{array}$ & $\begin{array}{r}1.00845704 \\
\pm .00000145\end{array}$ & $\begin{array}{r}1.00049609 \\
\pm .00003777\end{array}$ & $\begin{array}{r}64.491010 \\
\pm .000236\end{array}$ & $\begin{array}{r}269.440232 \\
\pm .000293\end{array}$ & $\begin{array}{r}132.187612 \\
\pm .000113\end{array}$ & $\begin{array}{r}-491.931566 \\
\pm 37.457531\end{array}$ \\
\hline & 19210421 & $\begin{array}{r}19210510.453240 \\
\pm .000810\end{array}$ & $\begin{array}{r}1.00843659 \\
\pm .00000434\end{array}$ & $\begin{array}{r}1.00018145 \\
\pm .00007412\end{array}$ & $\begin{array}{r}64.493716 \\
\pm .000563\end{array}$ & $\begin{array}{r}269.438264 \\
\pm .000509\end{array}$ & $\begin{array}{r}132.188366 \\
\pm .000185\end{array}$ & $\begin{array}{r}-179.930464 \\
\pm 73.500349\end{array}$ \\
\hline $22 \mathrm{U} 1$ & 102 & $\begin{array}{r}19221026.532142 \\
\pm .001333\end{array}$ & $\begin{array}{r}2.25878685 \\
\pm .00000759\end{array}$ & $\begin{array}{r}1.00079818 \\
\pm .00001927\end{array}$ & $\begin{array}{r}118.298884 \\
\pm .000483\end{array}$ & $\begin{array}{r}221.578280 \\
\pm .000054\end{array}$ & $\begin{array}{r}51.456548 \\
\pm .000036\end{array}$ & $\begin{array}{r}-353.365654 \\
\pm 8.530040\end{array}$ \\
\hline $\mathrm{C} / 1$ & 907 & $\begin{array}{r}19250906.941564 \\
\pm .003963\end{array}$ & $\begin{array}{r}4.18078079 \\
\pm .00002336\end{array}$ & $\begin{array}{r}1.00243417 \\
\pm .00003527\end{array}$ & $\begin{array}{r}205.759883 \\
\pm .000570\end{array}$ & $\begin{array}{r}358.539358 \\
\pm .000095\end{array}$ & $\begin{array}{r}146.713185 \\
\pm .000143\end{array}$ & $\begin{array}{r}-582.227554 \\
\pm 8.429946\end{array}$ \\
\hline C/1925 G1 & 19250331 & $\begin{array}{r}19250401.506580 \\
\pm .000240\end{array}$ & $\begin{array}{r}1.10948315 \\
\pm .00000309\end{array}$ & $\begin{array}{r}1.00060414 \\
\pm .00000642\end{array}$ & $\begin{array}{r}36.181542 \\
\pm .000283\end{array}$ & $\begin{array}{r}319.109303 \\
\pm .000059\end{array}$ & $\begin{array}{r}100.022632 \\
\pm .000080\end{array}$ & $\begin{array}{r}-544.519568 \\
\pm 5.784550\end{array}$ \\
\hline C/1925 W1 & 19251017 & $\begin{array}{r}19251002.973357 \\
\pm .000325\end{array}$ & $\begin{array}{r}1.56621518 \\
\pm .00001487\end{array}$ & $\begin{array}{r}1.00037453 \\
\pm .00001486\end{array}$ & $\begin{array}{r}106.398480 \\
\pm .000589\end{array}$ & $\begin{array}{r}335.612555 \\
\pm .000042\end{array}$ & $\begin{array}{r}49.329746 \\
\pm .000404\end{array}$ & $\begin{array}{r}-239.133330 \\
\pm 9.487854\end{array}$ \\
\hline C/1932 M1 & 19320910 & $\begin{array}{r}19320924.551075 \\
\pm .000982\end{array}$ & $\begin{array}{r}1.64736493 \\
\pm .00001195\end{array}$ & $\begin{array}{r}1.00046840 \\
\pm .00003229\end{array}$ & $\begin{array}{r}69.787385 \\
\pm .000647\end{array}$ & $\begin{array}{r}246.090506 \\
\pm .000230\end{array}$ & $\begin{array}{r}78.388394 \\
\pm .000200\end{array}$ & $\begin{array}{r}-284.333505 \\
\pm 19.598751\end{array}$ \\
\hline C/1932 M2 & 19320910 & $\begin{array}{r}19320921.074056 \\
\pm .000474\end{array}$ & $\begin{array}{r}2.31356998 \\
\pm .00000273\end{array}$ & $\begin{array}{r}1.00140517 \\
\pm .00000708\end{array}$ & $\begin{array}{r}329.693866 \\
\pm .000143\end{array}$ & $\begin{array}{r}216.093463 \\
\pm .000057\end{array}$ & $\begin{array}{r}124.988856 \\
\pm .000050\end{array}$ & $\begin{array}{r}-607.359409 \\
\pm 3.060104\end{array}$ \\
\hline C/1935 Q1 & 19360422 & $\begin{array}{r}19360511.635659 \\
\pm .001683\end{array}$ & $\begin{array}{r}4.04341779 \\
\pm .00000969\end{array}$ & $\begin{array}{r}1.00206616 \\
\pm .00002076\end{array}$ & $\begin{array}{r}44.895725 \\
\pm .000252\end{array}$ & $\begin{array}{r}300.561472 \\
\pm .000059\end{array}$ & $\begin{array}{r}66.112186 \\
\pm .000052\end{array}$ & $\begin{array}{r}-510.993085 \\
\pm 5.131166\end{array}$ \\
\hline C/1937 C1 & 19370706 & $\begin{array}{r}19370620.063073 \\
\pm .000498\end{array}$ & $\begin{array}{r}1.73378655 \\
\pm .00000401\end{array}$ & $\begin{array}{r}1.00014288 \\
\pm .00001263\end{array}$ & $\begin{array}{r}107.734884 \\
\pm .000305\end{array}$ & $\begin{array}{r}128.608042 \\
\pm .000110\end{array}$ & $\begin{array}{r}41.551513 \\
\pm .000084\end{array}$ & $\begin{array}{r}-82.409381 \\
\pm 7.285233\end{array}$ \\
\hline
\end{tabular}

Notes. The successive columns signify (1) - comet designation; (2) - epoch, that is, osculation date; (3) - perihelion time [TT]; (4) - perihelion distance; (5) - eccentricity; (6) - argument of perihelion (in degrees), equinox 2000.0; (7) - longitude of the ascending node (in degrees), equinox 2000.0; (8) - inclination (in degrees), equinox 2000.0; (9) - reciprocal semi-major axis in units of $10^{-6} \mathrm{AU}^{-1}$. Osculating orbits determined using the NG model of motion are indicated by light grey shading. 
Table B.1. continued.

\begin{tabular}{|c|c|c|c|c|c|c|c|c|}
\hline Comet & $\begin{array}{c}\text { Epoch } \\
\text { [yyyymmdd] } \\
(2)\end{array}$ & $\begin{array}{r}T \\
\text { [yyyymmdd.dddddd] } \\
(3)\end{array}$ & $\begin{array}{r}q \\
{[\mathrm{AU}]} \\
(4)\end{array}$ & (5) & $\begin{array}{l}\omega \\
{\left[{ }^{\circ}\right]} \\
(6)\end{array}$ & $\begin{array}{l}\Omega \\
{\left[{ }^{\circ}\right]} \\
(7)\end{array}$ & $\begin{array}{r}i \\
{\left[{ }^{\circ}\right]} \\
(8)\end{array}$ & $\begin{array}{r}1 / a_{\text {osc }} \\
{\left[10^{-6} \mathrm{AU}^{-1}\right]} \\
(9)\end{array}$ \\
\hline & 19370706 & $\begin{array}{r}19370620.061675 \\
\pm .000746\end{array}$ & $\begin{array}{l}1.73378562 \\
\pm .00000410\end{array}$ & $\begin{array}{r}1.00014873 \\
\pm .00001307\end{array}$ & $\begin{array}{r}107.734189 \\
\pm .000445\end{array}$ & $\begin{array}{r}128.607821 \\
\pm .000150\end{array}$ & $\begin{array}{r}41.551548 \\
\pm .000089\end{array}$ & $\begin{array}{r}-85.786161 \\
\pm 7.541101\end{array}$ \\
\hline C/1937 N1 & 19370815 & $\begin{array}{r}19370815.665333 \\
\pm .000189\end{array}$ & $\begin{array}{r}0.86274422 \\
\pm .00000040\end{array}$ & $\begin{array}{r}1.00005979 \\
\pm .00003586\end{array}$ & $\begin{array}{r}114.835849 \\
\pm .000396\end{array}$ & $\begin{array}{r}59.420445 \\
\pm .000220\end{array}$ & $\begin{array}{r}146.415278 \\
\pm .000197\end{array}$ & $\begin{array}{l}-69.304214 \\
\pm 41.563567\end{array}$ \\
\hline & 19370815 & $\begin{array}{r}19370815.666463 \\
\pm .000525\end{array}$ & $\begin{array}{l}0.86274100 \\
\pm .00000111\end{array}$ & $\begin{array}{r}0.99976776 \\
\pm .00010937\end{array}$ & $\begin{array}{r}114.837745 \\
\pm .001203\end{array}$ & $\begin{array}{r}59.421272 \\
\pm .000665\end{array}$ & $\begin{array}{r}146.416972 \\
\pm .000529\end{array}$ & $\begin{array}{r}269.188447 \\
\pm 126.765790\end{array}$ \\
\hline C/1940 R2 & 19410106 & $\begin{array}{r}19410116.233869 \\
\pm .000068\end{array}$ & $\begin{array}{r}0.36774076 \\
\pm .00000272\end{array}$ & $\begin{array}{r}1.00050751 \\
\pm .00000650\end{array}$ & $\begin{array}{r}199.568992 \\
\pm .000117\end{array}$ & $\begin{array}{r}296.590441 \\
\pm .000141\end{array}$ & $\begin{array}{r}49.894827 \\
\pm .000173\end{array}$ & $\begin{array}{r}-1380.069563 \\
\pm 17.681186\end{array}$ \\
\hline & 19410106 & $\begin{array}{r}19410116.234772 \\
\pm .000092\end{array}$ & $\begin{array}{l}0.36774724 \\
\pm .00000232\end{array}$ & $\begin{array}{l}1.00040431 \\
\pm .00001067\end{array}$ & $\begin{array}{r}199.570995 \\
\pm .000226\end{array}$ & $\begin{array}{r}296.590817 \\
\pm .000180\end{array}$ & $\begin{array}{r}49.893846 \\
\pm .000157\end{array}$ & $\begin{array}{r}-1099.416086 \\
\pm 29.027267\end{array}$ \\
\hline C/1940 S1 & 19400730 & $\begin{array}{r}19400815.741520 \\
\pm .018720\end{array}$ & $\begin{array}{r}1.06134353 \\
\pm .00042312\end{array}$ & $\begin{array}{r}1.00101170 \\
\pm .00044419\end{array}$ & $\begin{array}{r}329.641162 \\
0.036347\end{array}$ & $\begin{array}{r}128.060306 \\
\pm .006071\end{array}$ & $\begin{array}{r}133.112612 \\
\pm .001116\end{array}$ & $\begin{array}{l}-953.224013 \\
\pm 418.312774\end{array}$ \\
\hline C/1941 K1 & 19410903 & $\begin{array}{r}19410903.184122 \\
\pm .000051\end{array}$ & $\begin{array}{l}0.87479022 \\
\pm .00000031\end{array}$ & $\begin{array}{r}1.00026410 \\
\pm .00000216\end{array}$ & $\begin{array}{r}85.321879 \\
\pm .000038\end{array}$ & $\begin{array}{r}257.559607 \\
\pm .000024\end{array}$ & $\begin{array}{r}94.517037 \\
\pm .000106\end{array}$ & $\begin{array}{r}-301.899679 \\
\pm 2.473802\end{array}$ \\
\hline C/1942 C1 & 19420501 & $\begin{array}{r}19420430.833684 \\
\pm .000116\end{array}$ & $\begin{array}{r}1.44530230 \\
\pm .00000079\end{array}$ & $\begin{array}{r}1.00088319 \\
\pm .00000480\end{array}$ & $\begin{array}{r}223.415778 \\
\pm .000076\end{array}$ & $\begin{array}{r}340.934552 \\
\pm .000017\end{array}$ & $\begin{array}{r}79.451905 \\
\pm .000063\end{array}$ & $\begin{array}{r}-611.075849 \\
\pm 3.321178\end{array}$ \\
\hline & 19420501 & $\begin{array}{r}19420430.834279 \\
\pm .000236\end{array}$ & $\begin{array}{r}1.44528980 \\
\pm .00000580\end{array}$ & $\begin{array}{r}1.00082711 \\
\pm .00002112\end{array}$ & $\begin{array}{r}223.416090 \\
\pm .000147\end{array}$ & $\begin{array}{r}340.934741 \\
\pm .000065\end{array}$ & $\begin{array}{r}79.451445 \\
\pm .000242\end{array}$ & $\begin{array}{r}-572.277141 \\
\pm 14.612225\end{array}$ \\
\hline C/1942 C2 & 19421008 & $\begin{array}{r}19420927.280025 \\
\pm .007703\end{array}$ & $\begin{array}{l}4.11339144 \\
\pm .00003196\end{array}$ & $\begin{array}{r}1.00316671 \\
\pm .00005609\end{array}$ & $\begin{array}{r}163.620216 \\
\pm .001441\end{array}$ & $\begin{array}{r}281.038570 \\
\pm .000853\end{array}$ & $\begin{array}{r}172.514474 \\
\pm .000124\end{array}$ & $\begin{array}{r}-769.854598 \\
\pm 13.624279\end{array}$ \\
\hline C/1944 K2 & 19440601 & $\begin{array}{r}19440717.611796 \\
\pm .001868\end{array}$ & $\begin{array}{l}2.22594125 \\
\pm .00001342\end{array}$ & $\begin{array}{r}1.00205322 \\
\pm .00002843\end{array}$ & $\begin{array}{r}336.973475 \\
\pm .000686\end{array}$ & $\begin{array}{r}203.500207 \\
\pm .000194\end{array}$ & $\begin{array}{r}95.004881 \\
\pm .000159\end{array}$ & $\begin{array}{r}-922.405433 \\
\pm 12.770486\end{array}$ \\
\hline C/1946 C1 & 19460410 & $\begin{array}{r}19460413.264312 \\
\pm .000368\end{array}$ & $\begin{array}{r}1.72412209 \\
\pm .00000318\end{array}$ & $\begin{array}{l}1.00114441 \\
\pm .00000801\end{array}$ & $\begin{array}{r}54.328447 \\
\pm .000213\end{array}$ & $\begin{array}{r}129.664999 \\
\pm .000056\end{array}$ & $\begin{array}{r}72.842650 \\
\pm .000056\end{array}$ & $\begin{array}{r}-663.763946 \\
\pm 4.644041\end{array}$ \\
\hline & 19460410 & $\begin{array}{r}19460413.262573 \\
\pm .000674\end{array}$ & $\begin{array}{l}1.72409711 \\
\pm .00000356\end{array}$ & $\begin{array}{r}1.00106980 \\
\pm .00000939\end{array}$ & $\begin{array}{r}54.327041 \\
\pm .000428\end{array}$ & $\begin{array}{r}129.665283 \\
\pm .000052\end{array}$ & $\begin{array}{r}72.842371 \\
\pm .000054\end{array}$ & $\begin{array}{r}-620.496849 \\
\pm 5.444341\end{array}$ \\
\hline C/1946 P1 & 19461027 & $\begin{array}{r}19461026.778759 \\
\pm .000498\end{array}$ & $\begin{array}{r}1.13610604 \\
\pm .00000296\end{array}$ & $\begin{array}{r}1.00076873 \\
\pm .00000562\end{array}$ & $\begin{array}{r}320.412716 \\
\pm .000277\end{array}$ & $\begin{array}{r}238.335364 \\
\pm .000188\end{array}$ & $\begin{array}{r}56.964608 \\
\pm .000062\end{array}$ & $\begin{array}{r}-676.638371 \\
\pm 4.943135\end{array}$ \\
\hline C/1946 U1 & 19470224 & $\begin{array}{r}19470207.362613 \\
\pm .000422\end{array}$ & $\begin{array}{l}2.40766593 \\
\pm .00000218\end{array}$ & $\begin{array}{r}1.00094633 \\
\pm .00001085\end{array}$ & $\begin{array}{r}348.624706 \\
\pm .000140\end{array}$ & $\begin{array}{r}35.558527 \\
\pm .000049\end{array}$ & $\begin{array}{r}108.174444 \\
\pm .000048\end{array}$ & $\begin{array}{r}-393.047880 \\
\pm 4.504928\end{array}$ \\
\hline & 19470224 & $\begin{array}{r}19470207.363185 \\
\pm .000519\end{array}$ & $\begin{array}{l}2.40764364 \\
\pm .00000786\end{array}$ & $\begin{array}{r}1.00089117 \\
\pm .00001917\end{array}$ & $\begin{array}{r}348.624923 \\
\pm .000177\end{array}$ & $\begin{array}{r}35.558720 \\
\pm .000068\end{array}$ & $\begin{array}{r}108.174352 \\
\pm .000051\end{array}$ & $\begin{array}{r}-370.143668 \\
\pm 7.800650\end{array}$ \\
\hline C/1947 S1 & 19480219 & $\begin{array}{r}19480216.423429 \\
\pm .000066\end{array}$ & $\begin{array}{l}0.74812370 \\
\pm .00000075\end{array}$ & $\begin{array}{l}1.00035570 \\
\pm .00000258\end{array}$ & $\begin{array}{r}350.214858 \\
\pm .000179\end{array}$ & $\begin{array}{r}271.439960 \\
\pm .000229\end{array}$ & $\begin{array}{r}140.568349 \\
\pm .000078\end{array}$ & $\begin{array}{r}-475.455030 \\
\pm 3.453175\end{array}$ \\
\hline & 19480219 & $\begin{array}{r}19480216.422309 \\
\pm .000138\end{array}$ & $\begin{array}{l}0.74810617 \\
\pm .00000196\end{array}$ & $\begin{array}{r}1.00023485 \\
\pm .00001240\end{array}$ & $\begin{array}{r}350.213385 \\
\pm .000206\end{array}$ & $\begin{array}{r}271.439361 \\
\pm .000208\end{array}$ & $\begin{array}{r}140.568516 \\
\pm .000062\end{array}$ & $\begin{array}{r}-313.924888 \\
\pm 16.575559\end{array}$ \\
\hline C/1947 Y & 19480219 & $\begin{array}{r}19480216.691915 \\
\pm .000266\end{array}$ & $\begin{array}{r}1.49955491 \\
\pm .00000327\end{array}$ & $\begin{array}{r}1.00108229 \\
\pm .00001286\end{array}$ & $\begin{array}{r}61.923925 \\
\pm .000215\end{array}$ & $\begin{array}{r}199.300972 \\
\pm .000072\end{array}$ & $\begin{array}{r}77.533200 \\
\pm .000061\end{array}$ & $\begin{array}{r}-721.741506 \\
\pm 8.577917\end{array}$ \\
\hline C/1948 E1 & 19480509 & $\begin{array}{r}19480516.612175 \\
\pm .000281\end{array}$ & $\begin{array}{l}2.10705582 \\
\pm .00000236\end{array}$ & $\begin{array}{r}1.00077771 \\
\pm .00000570\end{array}$ & $\begin{array}{r}66.898096 \\
\pm .000124\end{array}$ & $\begin{array}{r}247.652645 \\
\pm .000043\end{array}$ & $\begin{array}{r}92.919469 \\
\pm .000032\end{array}$ & $\begin{array}{r}-369.095825 \\
\pm 2.703396\end{array}$ \\
\hline $\mathrm{C} / 1948 \mathrm{~T} 1$ & 19470912 & $\begin{array}{r}19470904.429515 \\
\pm .010323\end{array}$ & $\begin{array}{r}3.26110877 \\
\pm .00011350\end{array}$ & $\begin{array}{r}1.00227683 \\
\pm .00003289\end{array}$ & $\begin{array}{r}73.464822 \\
\pm .001866\end{array}$ & $\begin{array}{r}122.120668 \\
\pm .000217\end{array}$ & $\begin{array}{r}155.077948 \\
\pm .000265\end{array}$ & $\begin{array}{r}-698.175954 \\
\pm 10.071964\end{array}$ \\
\hline C/1950 K1 & 19510203 & $\begin{array}{r}19510115.043740 \\
\pm .000378\end{array}$ & $\begin{array}{r}2.57232857 \\
\pm .00000139\end{array}$ & $\begin{array}{r}1.00121061 \\
\pm .00000556\end{array}$ & $\begin{array}{r}192.468633 \\
\pm .000092\end{array}$ & $\begin{array}{r}38.890330 \\
\pm .000047\end{array}$ & $\begin{array}{r}144.155175 \\
\pm .000031\end{array}$ & $\begin{array}{r}-470.626833 \\
\pm 2.161805\end{array}$ \\
\hline
\end{tabular}

Table B.2. NG parameters derived in NG orbital solutions given in Table B.1.

\begin{tabular}{lcccc}
\hline \hline Comet & \multicolumn{2}{c}{ NG parameters defined by Eq. (2) in units of $10^{-8} \mathrm{AU}_{\text {day }}{ }^{-2}$} & $\tau$ \\
& $A_{1}$ & $A_{2}$ & $A_{3}$ & [days] \\
$(1)$ & $(2)$ & $(3)$ & - & $(5)$ \\
\hline C/1906 B1 & $7.323 \pm 1.841$ & - & - & - \\
C/1911 S3 & $3.930 \pm 0.798$ & - & - & - \\
C/1913 Y1 & $1.240 \pm 0.172$ & - & $2.481 \pm 0.826$ & - \\
C/1914 F1 & $4.834 \pm 0.681$ & $4.85 \pm 1.19$ & $-0.2692 \pm 0.0699$ & - \\
C/1916 G1 & $2.502 \pm 0.442$ & $0.708 \pm 0.363$ & - & - \\
C/1921 E1 & $3.155 \pm 0.629$ & $-0.451 \pm 0.861$ & - & - \\
C/1937 C1 & $2.146 \pm 0.968$ & $-0.002 \pm 0.452$ & - & - \\
C/1937 N1 & $1.976 \pm 0.495$ & $2.115 \pm 0.883$ & $-0.102 \pm 0.193$ & - \\
C/1940 R2 & $1.426 \pm 0.155$ & $-0.0392 \pm 0.0598$ & - & - \\
C/1942 C1 & $1.150 \pm 0.545$ & $-0.322 \pm 0.229$ & $-0.739 \pm 0.252$ & - \\
C/1946 C1 & $1.857 \pm 0.540$ & $3.434 \pm 0.409$ & - & - \\
C/1946 U1 & $13.03 \pm 4.61$ & - & - & \\
C/1947 S1 & $2.055 \pm 0.207$ & $-2.3409 \pm 0.0649$ & & -
\end{tabular}




\section{Appendix C: Original and future barycentric inverse semi-major axes and orbit-quality assessment}

Table C.1. Values of original and future barycentric, reciprocal semi-major axes in comparison to values published in MW08, and comparison of data used (Col. (3)) and orbit-quality assessment (Cols. (2) and (11)-(12)).

\begin{tabular}{|c|c|c|c|c|c|c|c|c|c|c|c|}
\hline \multirow{2}{*}{$\begin{array}{l}\text { Comet } \\
\text { (1) }\end{array}$} & \multicolumn{5}{|c|}{ Marsden \& Williams Catalogue (MW08) } & \multicolumn{2}{|c|}{ Present Catalogue } & \multicolumn{2}{|c|}{ the new results } & \multirow[b]{2}{*}{$\begin{array}{l}\text { MSE } \\
\text { class } \\
(11)\end{array}$} & \multirow[b]{2}{*}{$\begin{array}{l}\text { New } \\
\text { clas } \\
(12)\end{array}$} \\
\hline & $\begin{array}{l}\text { MSE } \\
\text { class } \\
(2)\end{array}$ & $\begin{array}{l}\text { Per cent of } \\
\text { residuals used } \\
\text { (3) }\end{array}$ & $\begin{array}{l}1 / a_{\text {ori }} \\
\text { in units } \\
\text { (4) }\end{array}$ & $\begin{array}{l}1 / a_{\text {osc }} \\
\text { s of } 10^{-6} \\
(5)\end{array}$ & $\begin{array}{l}1 / a_{\text {fut }} \\
\mathrm{AU}^{-1} \\
(6)\end{array}$ & $\begin{array}{l}1 / a_{\text {ori }} \\
\text { i n u n i t s } \\
\text { (7) }\end{array}$ & $\begin{array}{cc} & 1 / a_{\text {fut }} \\
\text { of } & 10^{-6} \mathrm{AU}^{-1} \\
& (8)\end{array}$ & $\begin{array}{l}\mathrm{rms} \\
{\left[{ }^{\prime \prime}\right]} \\
(9)\end{array}$ & $\begin{array}{l}\text { No. of } \\
\text { res. } \\
(10)\end{array}$ & & \\
\hline $\mathrm{C} / 1902 \mathrm{R} 1$ & 1B & 80 & 27 & 79 & 865 & $31.04 \pm 1.71$ & $870.94 \pm 1.71$ & 2.28 & 2501 & $1 \mathrm{~A}$ & $1 \mathrm{~b}$ \\
\hline $\mathrm{C} / 1902 \mathrm{X} 1$ & 1B & 29 & 26 & -218 & -488 & $74.03 \pm 7.25$ & $-439.81 \pm 7.24$ & 1.66 & 1307 & 1B & $1 \mathrm{~b}$ \\
\hline C/1903 M1 & 1B & 45 & 33 & -1230 & -1000 & $24.12 \pm 9.55$ & $-1010.00 \pm 9.55$ & 2.03 & 1021 & 1B & $2 \mathrm{a}$ \\
\hline C/1904 Y1 & $2 \mathrm{~A}$ & 32 & -75 & -360 & 170 & $101 . \pm 117$ & $348 . \pm 117$ & 2.87 & 302 & $2 \mathrm{~A}$ & $2 b$ \\
\hline \multirow[t]{2}{*}{ C/1906 B1 } & $1 \mathrm{~B}$ & 83 & -75 & -857 & -343 & $-135.59 \pm 22.96$ & $-402.66 \pm 22.97$ & 3.07 & 450 & 1B & $2 \mathrm{a}$ \\
\hline & & & & & & $117.32: 73.86$ & $-149.58: 73.87$ & 3.05 & 449 & 1B & $2 a$ \\
\hline C/1906 E1* & $1 \mathrm{~B}$ & 123 & 28 & -452 & -519 & $17.35 \pm 5.55$ & $-529.52 \pm 5.54$ & 1.96 & 812 & $1 \mathrm{~A}$ & 1a \\
\hline C/1907 E1 & $1 \mathrm{~B}$ & 45 & 25 & -489 & -290 & $33.76 \pm 21.56$ & $-281.04 \pm 21.55$ & 2.56 & 296 & 1B & $2 \mathrm{a}$ \\
\hline \multirow[t]{2}{*}{ C/1911 S3 } & $2 \mathrm{~A}$ & 54 & -74 & -483 & +175 & $-163.8 \pm 36.8$ & $80.7 \pm 36.8$ & 2.35 & 246 & $2 \mathrm{~A}$ & $2 \mathrm{a}$ \\
\hline & & & & & & 796. : 205. & 1041.: 205 & 2.10 & 244 & $2 \mathrm{~B}$ & $2 b$ \\
\hline C/1912 R1 & 1B & 20 & 45 & -630 & -363 & $36.77 \pm 5.27$ & $-370.81 \pm 5.27$ & 2.48 & 1670 & 1B & $1 \mathrm{~b}$ \\
\hline \multirow[t]{2}{*}{ C/1913 Y1 } & $1 \mathrm{~A}$ & 36 & 29 & -140 & 063 & $22.14 \pm 1.30$ & $56.41 \pm 1.30$ & 2.06 & 1874 & $1 \mathrm{~A}$ & 1a \\
\hline & & & & & & $52.57: 4.23$ & $86.84: 4.23$ & 2.00 & 1860 & $1 \mathrm{~A}$ & 1a \\
\hline \multirow[t]{2}{*}{ C/1914 F1 } & $2 \mathrm{~A}$ & 24 & 126 & -88 & 1561 & $57.45 \pm 28.41$ & $1492.0 \pm 28.4$ & 3.33 & 517 & $2 \mathrm{~A}$ & $2 a$ \\
\hline & & & & & & 600.: 152. & $1475.8: 37.7$ & 3.12 & 519 & $2 \mathrm{~A}$ & $2 b$ \\
\hline C/1914 M1* & $1 \mathrm{~A}$ & 64 & 27 & -878 & -1 & $36.6 \pm 25.9$ & $8.5 \pm 25.0$ & 2.21 & 122 & 1B & $1 \mathrm{~b}$ \\
\hline \multirow[t]{2}{*}{ C/1916 G1 } & $1 \mathrm{~A}$ & 45 & 17 & 353 & 763 & $35.33 \pm 3.20$ & $781.41 \pm 3.20$ & 1.97 & 823 & $1 \mathrm{~A}$ & 1a \\
\hline & & & & & & $69.59: 9.48$ & $783.75: 8.79$ & 1.84 & 817 & $1 \mathrm{~A}$ & $1 b$ \\
\hline C/1919 Q2 & $2 \mathrm{~A}$ & 35 & 20 & -199 & -42 & $34.7 \pm 67.3$ & $-26.9 \pm 67.3$ & 2.58 & 498 & $2 \mathrm{~A}$ & $2 \mathrm{a}$ \\
\hline \multirow[t]{2}{*}{ C/1921 E1 } & $1 \mathrm{~B}$ & 32 & 18 & -354 & -351 & $-120.1 \pm 37.6$ & $-488.8 \pm 37.4$ & 3.27 & 914 & 1B & $2 \mathrm{a}$ \\
\hline & & & & & & $85.9: 80.8$ & $-210.9: 96.6$ & 3.25 & 914 & 1B & $2 a$ \\
\hline C/1922 U1 & $1 \mathrm{~A}$ & 45 & 21 & -334 & -523 & $2.35 \pm 8.52$ & $-542.13 \pm 8.51$ & 1.82 & 826 & $1 \mathrm{~A}$ & $1 b$ \\
\hline $\mathrm{C} / 1925 \mathrm{~F} 1 *$ & $1 \mathrm{~A}$ & 25 & 35 & -582 & 128 & $34.83 \pm 8.45$ & $127.96 \pm 8.45$ & 2.75 & 463 & $1 \mathrm{~A}$ & $1 \mathrm{~b}$ \\
\hline C/1925 G1 & $1 \mathrm{~A}$ & 42 & 40 & -545 & -533 & $40.03 \pm 5.74$ & $-532.49 \pm 5.74$ & 2.79 & 964 & $1 \mathrm{~A}$ & $1 \mathrm{~b}$ \\
\hline C/1925 W1 & $1 \mathrm{~B}$ & 44 & 24 & -244 & -322 & $28.59 \pm 9.62$ & $-317.76 \pm 9.61$ & 1.94 & 593 & 1B & $1 b$ \\
\hline C/1932 M1 & $1 \mathrm{~B}$ & 30 & -56 & -365 & -327 & $24.21 \pm 19.40$ & $-245.8 \pm 19.4$ & 2.60 & 325 & $1 \mathrm{~B}$ & $1 b$ \\
\hline C/1932 M2 & $1 \mathrm{~A}$ & 59 & 45 & -619 & -240 & $56.58 \pm 3.07$ & $-229.01 \pm 3.07$ & 1.77 & 546 & $1 \mathrm{~A}$ & 1a \\
\hline C/1935 Q1* & $1 \mathrm{~A}$ & 86 & 19 & -506 & -281 & $13.16 \pm 5.19$ & $-285.68 \pm 5.19$ & 1.49 & 250 & $1 \mathrm{~A}$ & $1 \mathrm{a}$ \\
\hline \multirow[t]{2}{*}{$\mathrm{C} / 1937 \mathrm{C} 1$} & $1 \mathrm{~B}$ & 35 & 62 & -79 & 1400 & $58.40 \pm 7.16$ & $1396.88 \pm 7.17$ & 2.53 & 767 & $1 \mathrm{~B}$ & $1 \mathrm{~b}$ \\
\hline & & & & & & $44.8: 14.4$ & $1383.3: 11.7$ & 2.48 & 766 & 1B & $1 \mathrm{~b}$ \\
\hline \multirow[t]{2}{*}{ C/1937 N1 } & $2 \mathrm{~A}$ & 55 & 124 & 17 & 281 & $37.3 \pm 40.5$ & $194.2 \pm 40.5$ & 2.05 & 765 & $2 \mathrm{~A}$ & $2 \mathrm{a}$ \\
\hline & & & & & & 507.: 101. & 231.: 172. & 1.92 & 766 & $2 \mathrm{~A}$ & $2 a$ \\
\hline \multirow{2}{*}{ C/1940 R2 } & 1B & 56 & 1 & -1319 & -1570 & $-60.0 \pm 17.7$ & $-1630.6 \pm 17.7$ & 1.77 & 678 & 1B & $1 \mathrm{~b}$ \\
\hline & & & & & & $51.6: 17.1$ & $-1494.0: 35.7$ & 1.49 & 670 & 1B & $1 \mathrm{~b}$ \\
\hline C/1940 S1 & $2 \mathrm{~B}$ & 62 & -124 & -1374 & -1123 & $297 . \pm 427$ & $-703 . \pm 427$ & 3.67 & 61 & $2 \mathrm{~A}$ & $2 b$ \\
\hline C/1941 K1 & $1 \mathrm{~B}$ & 79 & 78 & -278 & 190 & $53.89 \pm 2.47$ & $166.22 \pm 2.47$ & 2.22 & 801 & $1 \mathrm{~A}$ & $1 b$ \\
\hline \multirow[t]{2}{*}{ C/1942 C1 } & $1 \mathrm{~B}$ & 111 & 16 & -618 & -821 & $22.60 \pm 3.33$ & $-813.98 \pm 3.33$ & 1.46 & 412 & $1 \mathrm{~A}$ & $1 \mathrm{a}$ \\
\hline & & & & & & $37.0: 15.6$ & $-775.68: 8.58$ & 1.23 & 411 & $1 \mathrm{~A}$ & $1 \mathrm{~b}$ \\
\hline C/1942 C2* & $1 \mathrm{~A}$ & 80 & -34 & -774 & -282 & $-29.1 \pm 13.5$ & $-278.3 \pm 13.5$ & 1.57 & 88 & $1 \mathrm{~A}$ & $1 \mathrm{~b}$ \\
\hline C/1944 K2 & $1 \mathrm{~A}$ & 89 & 18 & -937 & -522 & $20.8 \pm 12.8$ & $-518.7 \pm 12.8$ & 1.58 & 56 & $1 \mathrm{~A}$ & $1 \mathrm{~b}$ \\
\hline \multirow[t]{2}{*}{$\mathrm{C} / 1946 \mathrm{C} 1$} & $1 \mathrm{~A}$ & 43 & -13 & -678 & 373 & $0.80 \pm 4.60$ & $386.97 \pm 4.60$ & 2.54 & 857 & $1 \mathrm{~A}$ & 1a \\
\hline & & & & & & $102.4: 12.7$ & $346.80: 5.61$ & 2.17 & 848 & $1 \mathrm{~A}$ & $1 \mathrm{~b}$ \\
\hline C/1946 P1 & $1 \mathrm{~A}$ & 79 & 44 & -683 & 16 & $50.86 \pm 5.08$ & $22.55 \pm 5.08$ & 0.99 & 257 & $1 \mathrm{~A}$ & 1a \\
\hline C/1946 U1 & $1 \mathrm{~A}$ & 75 & -1 & -393 & 26 & $-0.59 \pm 4.54$ & $26.22 \pm 4.54$ & 1.25 & 259 & $1 \mathrm{~A}$ & 1a \\
\hline & & & & & & $17.08: 6.52$ & $43.88: 6.52$ & 1.19 & 259 & 1B & $1 \mathrm{~b}$ \\
\hline C/1947 S1 & $1 \mathrm{~A}$ & 45 & 24 & -485 & -366 & $33.34 \pm 3.46$ & $-356.31 \pm 3.46$ & 2.59 & 546 & $1 \mathrm{~A}$ & $1 \mathrm{a}$ \\
\hline & & & & & & $53.02: 8.19$ & $-277.6: 11.7$ & 2.42 & 543 & $1 \mathrm{~A}$ & $1 \mathrm{~b}$ \\
\hline C/1947 Y1 & 1B & 76 & 28 & -724 & 53 & $28.89 \pm 8.49$ & $54.31 \pm 8.50$ & 1.22 & 204 & 1B & $1 \mathrm{~b}$ \\
\hline C/1948 E1 & $1 \mathrm{~A}$ & 44 & 34 & -373 & 31 & $37.25 \pm 2.74$ & $35.21 \pm 2.74$ & 1.48 & 431 & $1 \mathrm{~A}$ & $1 \mathrm{a}$ \\
\hline $\mathrm{C} / 1948 \mathrm{~T} 1 *$ & $1 \mathrm{~A}$ & 100 & 34 & -699 & 225 & $34.2 \pm 10.0$ & $225.0 \pm 10.0$ & 0.94 & 52 & $1 \mathrm{~A}$ & $1 b$ \\
\hline C/1950 K1 & $1 \mathrm{~A}$ & 16 & 37 & -479 & 270 & $45.1 \pm 2.2$ & $278.4 \pm 2.2$ & 1.28 & 466 & $1 \mathrm{~A}$ & $1 \mathrm{a}$ \\
\hline
\end{tabular}

Notes. Columns (4)-(6) show values of $1 / a_{\mathrm{ori}}, 1 / a_{\mathrm{osc}}$ and $1 / a_{\mathrm{fut}}$ taken from MW08, Cols. (7)-(8) give values of $1 / a_{\mathrm{ori}}$ and $1 / a_{\mathrm{fut}}$ and their uncertainties derived in the present investigation. NG solutions are given in the second row of these comets when these solutions were possible to determine. The rms and the number of residuals are additionally given in Cols. (9)-(10). In the last two columns the quality class assessments are presented using the standard MSE method (Col. (12)), and the new revised method proposed by Królikowska \& Dybczyński (Col. (13)). Column (3) shows the per cent of residuals used in MW08 in comparison to residuals used here for each comet (compare Col. (10) with twice as many as given in Col. (9) of Table A.1). NG models are indicated by light grey shading, an asterisk in Col. (1) indicates comets with large perihelion distances. For more details see the text. 
A\&A 571, A63 (2014)

\section{Appendix D: Original barycentric orbital elements}

Table D.1. Orbital elements of original barycentric orbits, that is, before entering the planetary zone for all models described in Table C.1.

\begin{tabular}{|c|c|c|c|c|c|c|c|c|}
\hline Comet & $\begin{array}{c}\text { Epoch } \\
\text { [yyyymmdd] } \\
(2)\end{array}$ & $\begin{array}{r}T \\
\text { [yyyymmdd.dddddd] } \\
(3)\end{array}$ & $\begin{array}{r}q \\
{[\mathrm{AU}]} \\
(4)\end{array}$ & (5) & $\begin{array}{l}\omega \\
{\left[{ }^{\circ}\right]} \\
(6)\end{array}$ & $\begin{array}{l}\Omega \\
{\left[{ }^{\circ}\right]} \\
(7)\end{array}$ & $\begin{array}{r}i \\
{\left[{ }^{\circ}\right]} \\
(8)\end{array}$ & $\begin{array}{r}1 / a_{\text {ori }} \\
{\left[10^{-6} \mathrm{AU}^{-1}\right]} \\
(9)\end{array}$ \\
\hline \multirow[t]{2}{*}{ C/1902 R1 } & 16050616 & 19021124.748046 & 0.39752997 & 0.99998766 & 152.968369 & 50.636389 & 156.486711 & 31.04 \\
\hline & & \pm 0.000042 & \pm 0.00000028 & \pm 0.00000067 & \pm 0.000084 & \pm 0.000087 & \pm 0.000040 & \pm 1.71 \\
\hline \multirow{2}{*}{ C/1902 X1 } & 16010128 & 19030324.059433 & 2.77648897 & 0.99979445 & 5.819304 & 118.884571 & 43.892926 & 74.03 \\
\hline & & \pm 0.002493 & \pm 0.00001348 & \pm 0.00002012 & \pm 0.000769 & \pm 0.000087 & \pm 0.000261 & \pm 7.25 \\
\hline \multirow[t]{2}{*}{ C/1903 M1 } & 16060611 & 19030826.871477 & 0.32438523 & 0.99999218 & 127.495100 & 294.778173 & 85.303818 & 24.12 \\
\hline & & \pm 0.000043 & \pm 0.00000159 & \pm 0.00000310 & \pm 0.000266 & \pm 0.000054 & \pm 0.000202 & \pm 9.55 \\
\hline \multirow{2}{*}{ C/1904 Y1 } & 16031204 & 19041103.420926 & 1.88656503 & 0.99980792 & 40.672000 & 219.740942 & 99.546209 & 101.81 \\
\hline & & \pm 0.013759 & \pm 0.00009818 & \pm 0.00022132 & \pm 0.006737 & \pm 0.000570 & \pm 0.000554 & \pm 117.32 \\
\hline \multirow[t]{4}{*}{ C/1906 B1 } & 16081107 & 19051222.176515 & 1.29645026 & 1.00017579 & 89.834094 & 287.548057 & 126.511964 & -135.59 \\
\hline & & \pm 0.000916 & \pm 0.00000337 & \pm 0.00002976 & \pm 0.000348 & \pm 0.000302 & \pm 0.000197 & \pm 22.96 \\
\hline & 16060102 & 19051222.173035 & 1.29627992 & 0.99984792 & 89.843280 & 287.549903 & 126.512022 & 117.32 \\
\hline & & \pm 0.001408 & \pm 0.00004429 & \pm 0.00009573 & \pm 0.002419 & \pm 0.000595 & \pm 0.000192 & \pm 73.86 \\
\hline \multirow[t]{2}{*}{ C/1906 E1 } & 16030518 & 19051017.833416 & 3.33691190 & 0.99994209 & 158.570127 & 343.735716 & 4.287970 & 17.35 \\
\hline & & \pm 0.001867 & \pm 0.00001423 & \pm 0.00001852 & \pm 0.000818 & \pm 0.000732 & \pm 0.000190 & \pm 5.55 \\
\hline \multirow[t]{2}{*}{ C/1907 E1 } & 16061012 & 19070320.532327 & 2.05146625 & 0.99993073 & 317.181114 & 98.439032 & 141.685157 & 33.76 \\
\hline & & \pm 0.001520 & \pm 0.00001619 & \pm 0.00004422 & \pm 0.000820 & \pm 0.000215 & \pm 0.000201 & \pm 21.55 \\
\hline \multirow{4}{*}{ C/1911 S3 } & 16160817 & 19111010.212422 & 0.30444763 & 1.00004987 & 71.678698 & 89.139025 & 96.440241 & -163.80 \\
\hline & & \pm 0.000557 & \pm 0.00000077 & \pm 0.00001120 & \pm 0.000389 & \pm 0.000420 & \pm 0.000553 & \pm 36.80 \\
\hline & 16050616 & 19111010.198180 & 0.30444215 & 0.99975759 & 71.680473 & 89.140777 & 96.445791 & 796.26 \\
\hline & & \pm 0.003218 & \pm 0.00000134 & \pm 0.00006235 & \pm 0.000499 & \pm 0.000521 & \pm 0.001329 & \pm 204.81 \\
\hline \multirow[t]{2}{*}{ C/1912 R1 } & 16140828 & 19121004.999276 & 0.71382525 & 0.99997375 & 25.719944 & 298.264840 & 79.846805 & 36.77 \\
\hline & & \pm 0.000056 & \pm 0.00000082 & \pm 0.00000376 & \pm 0.000110 & \pm 0.000112 & \pm 0.000085 & \pm 5.27 \\
\hline \multirow[t]{4}{*}{ C/1913 Y1 } & 16160310 & 19141025.816829 & 1.10070306 & 0.99997563 & 97.539554 & 60.475762 & 67.986327 & 22.14 \\
\hline & & \pm 0.000055 & \pm 0.00000079 & \pm 0.00000143 & \pm 0.000028 & \pm 0.000024 & \pm 0.000043 & \pm 1.30 \\
\hline & 16151111 & 19141025.817363 & 1.10067114 & 0.99994214 & 97.541763 & 60.475772 & 67.986634 & 52.57 \\
\hline & & \pm 0.000089 & \pm 0.00000460 & \pm 0.00000465 & \pm 0.000303 & \pm 0.000024 & \pm 0.000059 & \pm 4.23 \\
\hline \multirow[t]{4}{*}{ C/1914 F1 } & 16150425 & 19140604.671419 & 1.20014864 & 0.99993105 & 72.188980 & 200.123181 & 23.910787 & 57.45 \\
\hline & & \pm 0.000268 & \pm 0.00000515 & \pm 0.00003410 & \pm 0.000265 & \pm 0.000308 & \pm 0.000343 & \pm 28.41 \\
\hline & 16081107 & 19140604.688500 & 1.19991017 & 0.99928025 & 72.209576 & 200.117596 & 23.903136 & 599.84 \\
\hline & & \pm 0.003739 & \pm 0.00005139 & \pm 0.00018235 & \pm 0.004142 & \pm 0.001699 & \pm 0.002255 & \pm 151.99 \\
\hline \multirow{2}{*}{ C/1914 M1 } & 16110225 & 19140730.529118 & 3.74227102 & 0.99986307 & 14.115408 & 271.473680 & 71.078722 & 36.59 \\
\hline & & \pm 0.010705 & \pm 0.00006815 & \pm 0.00009344 & \pm 0.002097 & \pm 0.000169 & \pm 0.000424 & \pm 24.97 \\
\hline \multirow[t]{4}{*}{ C/1916 G1 } & 16170921 & 19170617.357661 & 1.69219889 & 0.99994022 & 120.502725 & 184.485105 & 25.605811 & 35.33 \\
\hline & & \pm 0.000249 & \pm 0.00000105 & \pm 0.00000541 & \pm 0.000140 & \pm 0.000054 & \pm 0.000045 & \pm 3.20 \\
\hline & 16170414 & 19170617.362353 & 1.69214922 & 0.99988224 & 120.505372 & 184.485407 & 25.605536 & 69.59 \\
\hline & & \pm 0.001103 & \pm 0.00000924 & \pm 0.00001603 & \pm 0.000640 & \pm 0.000122 & \pm 0.000064 & \pm 9.48 \\
\hline \multirow[t]{2}{*}{ C/1919 Q2 } & 16210324 & 19191207.325501 & 1.11815172 & 0.99996124 & 185.698259 & 122.175370 & 46.404177 & 34.67 \\
\hline & & \pm 0.002308 & \pm 0.00002761 & \pm 0.00007521 & \pm 0.002474 & \pm 0.000564 & \pm 0.000178 & \pm 67.26 \\
\hline \multirow[t]{4}{*}{ C/1921 E1 } & 16240706 & 19210510.690297 & 1.00693074 & 1.00012096 & 64.705467 & 269.587562 & 132.180302 & -120.12 \\
\hline & & \pm 0.000189 & \pm 0.00000143 & \pm 0.00003788 & \pm 0.000237 & \pm 0.000307 & \pm 0.000115 & \pm 37.62 \\
\hline & 16220319 & 19210510.691603 & 1.00687747 & 0.99991349 & 64.710041 & 269.585493 & 132.181074 & 85.92 \\
\hline & & \pm 0.001631 & \pm 0.00002269 & \pm 0.00008135 & \pm 0.002464 & \pm 0.000538 & \pm 0.000188 & \pm 80.79 \\
\hline \multirow[t]{2}{*}{ C/1922 U1 } & 16220607 & 19221025.586946 & 2.25655127 & 0.99999470 & 118.331242 & 221.632968 & 51.422827 & 2.35 \\
\hline & & 413 & \pm 0.00000784 & \pm 0.00001923 & \pm 0.000480 & \pm 0.000056 & 0036 & \pm 8.52 \\
\hline C/1925 F1 & 16210722 & 19250906.261864 & 4.17819249 & 0.99985439 & 205.622401 & 358.368841 & 146.741752 & 34.85 \\
\hline & & 957 & \pm 0.00002339 & \pm 0.00003480 & \pm 0.000574 & \pm 0.000093 & 00145 & \pm 8.33 \\
\hline C/1925 G1 & 16260626 & 19250331.956264 & 1.10542489 & 0.99995575 & 36.344786 & 319.188844 & 100.089542 & 40.03 \\
\hline & & \pm 0.000268 & \pm 0.00000304 & \pm 0.00000635 & \pm 0.000283 & \pm 0.000060 & \pm 0.000081 & \pm 5.75 \\
\hline C/1925 W1 & 16260407 & 19251002.714744 & 1.56532856 & 0.99995524 & 106.401280 & 335.706396 & 49.270625 & 28.59 \\
\hline & & \pm 0.000382 & \pm 0.00001534 & \pm 0.00001506 & \pm 0.000599 & \pm 0.000041 & \pm 0.000414 & \pm 9.62 \\
\hline C/1932 M1 & 16330301 & 19320923.758305 & 1.64447847 & 0.99996018 & 69.867810 & 246.157067 & 78.369050 & 24.21 \\
\hline & & \pm 0.001011 & \pm 0.00001183 & \pm 0.00003190 & \pm 0.000641 & \pm 0.000228 & \pm 0.000199 & \pm 19.40 \\
\hline C/1932 M2 & 16310819 & 19320921.542393 & 2.31250621 & 0.99986916 & 329.793942 & 216.089015 & 125.023427 & 56.58 \\
\hline & & \pm 0.000469 & \pm 0.00000275 & \pm 0.00000711 & \pm 0.000144 & \pm 0.000057 & \pm 0.000050 & \pm 3.07 \\
\hline C/1935 Q1 & 16320922 & 19360511.115435 & 4.03419814 & 0.99994692 & 45.035086 & 300.599583 & 66.129296 & 13.16 \\
\hline & & \pm 0.001724 & \pm 0.00000987 & \pm 0.00002094 & \pm 0.000250 & \pm 0.000060 & \pm 0.000051 & \pm 5.19 \\
\hline C/1937 C1 & 16370429 & 19370620.221049 & 1.73545046 & 0.99989864 & 107.714649 & 128.591694 & 41.523168 & 58.40 \\
\hline
\end{tabular}

Notes. The successive columns signify (1) - comet designation; (2) - epoch, that is, osculation date; (3) - perihelion time [TT]; (4) - perihelion distance; (5) - eccentricity; (6) - argument of perihelion (in degrees), equinox 2000.0; (7) - longitude of the ascending node (in degrees), equinox 2000.0; (8) - inclination (in degrees), equinox 2000.0; (9) - reciprocal original semi-major axis in units of $10^{-6} \mathrm{AU}^{-1}$. Original orbits determined using the NG model of motion are indicated by light grey shading. 
Table D.1. continued.

\begin{tabular}{|c|c|c|c|c|c|c|c|c|}
\hline Comet & $\begin{array}{c}\text { Epoch } \\
\text { [yyyymmdd] } \\
(2)\end{array}$ & $\begin{array}{r}T \\
\text { [yyyymmdd.dddddd] } \\
(3) \\
\end{array}$ & $\begin{array}{r}q \\
{[\mathrm{AU}]} \\
(4) \\
\end{array}$ & (5) & $\begin{array}{r}\omega \\
{\left[^{\circ}\right]} \\
(6) \\
\end{array}$ & $\begin{array}{r}\Omega \\
{\left[{ }^{\circ}\right]} \\
(7) \\
\end{array}$ & $\begin{array}{r}i \\
{\left[{ }^{\circ}\right]} \\
(8) \\
\end{array}$ & $\begin{array}{r}1 / a_{\text {ori }} \\
{\left[10^{-6} \mathrm{AU}^{-1}\right]} \\
(9) \\
\end{array}$ \\
\hline & & \pm 0.000506 & \pm 0.00000397 & \pm 0.00001243 & \pm 0.000300 & \pm 0.000109 & \pm 0.000084 & \pm 7.16 \\
\hline & 16370718 & 19370620.222929 & 1.73543405 & 0.99992220 & 107.716372 & 128.591468 & 41.523205 & 44.83 \\
\hline & & \pm 0.000968 & \pm 0.00000793 & \pm 0.00002491 & \pm 0.000841 & \pm 0.000156 & \pm 0.000090 & \pm 14.36 \\
\hline \multirow[t]{4}{*}{ C/1937 N1 } & 16390419 & 19370815.655572 & 0.85943419 & 0.99996793 & 114.977962 & 59.471335 & 146.361452 & 37.31 \\
\hline & & \pm 0.001324 & \pm 0.00000041 & \pm 0.00003482 & \pm 0.000370 & \pm 0.000201 & \pm 0.000205 & \pm 40.51 \\
\hline & 16331027 & 19370815.661527 & 0.85934606 & 0.99956398 & 114.991035 & 59.472210 & 146.363379 & 507.39 \\
\hline & & \pm 0.001656 & \pm 0.00002184 & \pm 0.00008654 & \pm 0.002703 & \pm 0.000809 & \pm 0.000573 & \pm 100.71 \\
\hline \multirow[t]{4}{*}{ C/1940 R2 } & 16440830 & 19410115.973517 & 0.36427644 & 1.00002186 & 199.546182 & 296.892318 & 50.185071 & -60.01 \\
\hline & & \pm 0.000159 & \pm 0.00000282 & \pm 0.00000646 & \pm 0.000115 & \pm 0.000141 & \pm 0.000168 & \pm 17.74 \\
\hline & 16430617 & 19410115.973647 & 0.36427385 & 0.99998121 & 199.547949 & 296.892704 & 50.184132 & 51.59 \\
\hline & & \pm 0.000186 & \pm 0.00000275 & \pm 0.00000624 & \pm 0.000223 & \pm 0.000181 & \pm 0.000151 & \pm 17.12 \\
\hline \multirow[t]{2}{*}{ C/1940 S1 } & 16381220 & 19400816.604848 & 1.06507308 & 0.99968363 & 329.678357 & 128.069124 & 133.275676 & 297.04 \\
\hline & & \pm 0.016026 & \pm 0.00043374 & \pm 0.00045458 & \pm 0.037243 & \pm 0.006470 & \pm 0.000940 & \pm 426.92 \\
\hline \multirow{2}{*}{ C/1941 K1 } & 16430217 & 19410903.211543 & 0.87864337 & 0.99995265 & 85.289643 & 257.546307 & 94.468456 & 53.89 \\
\hline & & \pm 0.000061 & \pm 0.00000031 & \pm 0.00000217 & \pm 0.000038 & \pm 0.000024 & \pm 0.000108 & \pm 2.47 \\
\hline \multirow[t]{4}{*}{ C/1942 C1 } & 16430217 & 19420430.110680 & 1.44096429 & 0.99996744 & 223.544907 & 341.080318 & 79.489648 & 22.60 \\
\hline & & \pm 0.000112 & \pm 0.00000076 & \pm 0.00000481 & \pm 0.000077 & \pm 0.000017 & \pm 0.000063 & \pm 3.33 \\
\hline & 16430108 & 19420430.111719 & 1.44094260 & 0.99994665 & 223.546319 & 341.080424 & 79.488513 & 37.02 \\
\hline & & \pm 0.000984 & \pm 0.00001325 & \pm 0.00002241 & \pm 0.001010 & \pm 0.000038 & \pm 0.000463 & \pm 15.55 \\
\hline \multirow[t]{2}{*}{ C/1942 C2 } & 16390708 & 19420928.842884 & 4.10696133 & 1.00011952 & 163.752994 & 281.002773 & 172.517772 & -29.10 \\
\hline & & \pm 0.007726 & \pm 0.00003147 & \pm 0.00005531 & \pm 0.001446 & \pm 0.000850 & \pm 0.000123 & \pm 13.47 \\
\hline \multirow[t]{2}{*}{ C/1944 K2 } & 16440105 & 19440718.501473 & 2.22564815 & 0.99995373 & 337.096904 & 203.525912 & 95.124917 & 20.79 \\
\hline & & \pm 0.001683 & \pm 0.00001298 & \pm 0.00002854 & \pm 0.000687 & \pm 0.000191 & \pm 0.000157 & \pm 12.82 \\
\hline \multirow[t]{4}{*}{ C/1946 C1 } & 16461108 & 19460412.084826 & 1.71681103 & 0.99999862 & 54.466561 & 129.577886 & 72.875740 & 0.80 \\
\hline & & \pm 0.000713 & \pm 0.00000306 & \pm 0.00000789 & \pm 0.000212 & \pm 0.000055 & \pm 0.000056 & \pm 4.60 \\
\hline & 16450825 & 19460412.089411 & 1.71675231 & 0.99982419 & 54.469479 & 129.578179 & 72.875457 & 102.41 \\
\hline & & \pm 0.000901 & \pm 0.00000645 & \pm 0.00002185 & \pm 0.000666 & \pm 0.000053 & \pm 0.000055 & \pm 12.73 \\
\hline \multirow[t]{2}{*}{ C/1946 P1 } & 16471103 & 19461026.493829 & 1.12948754 & 0.99994255 & 320.574302 & 238.295327 & 57.042068 & 50.86 \\
\hline & & \pm 0.000520 & \pm 0.00000300 & \pm 0.00000573 & \pm 0.000286 & \pm 0.000193 & \pm 0.000064 & \pm 5.07 \\
\hline \multirow[t]{4}{*}{ C/1946 U1 } & 16460601 & 19470206.851120 & 2.41089055 & 1.00000141 & 348.604392 & 35.566639 & 108.115380 & -0.59 \\
\hline & & \pm 0.000555 & \pm 0.00000216 & \pm 0.00001094 & \pm 0.000140 & \pm 0.000048 & \pm 0.000048 & \pm 4.54 \\
\hline & 16460422 & 19470206.857997 & 2.41085327 & 0.99995883 & 348.607122 & 35.566834 & 108.115289 & 17.08 \\
\hline & & \pm 0.002586 & \pm 0.00001313 & \pm 0.00001572 & \pm 0.001023 & \pm 0.000069 & \pm 0.000051 & \pm 6.52 \\
\hline \multirow[t]{4}{*}{ C/1947 S1 } & 16500111 & 19480217.010780 & 0.74919707 & 0.99997502 & 350.249194 & 271.413569 & 140.601343 & 33.34 \\
\hline & & \pm 0.000061 & \pm 0.00000076 & \pm 0.00000259 & \pm 0.000181 & \pm 0.000231 & \pm 0.000079 & \pm 3.46 \\
\hline & 16491023 & 19480217.009294 & 0.74915527 & 0.99996030 & 350.251157 & 271.412966 & 140.601506 & 52.99 \\
\hline & & \pm 0.000304 & \pm 0.00000502 & \pm 0.00000614 & \pm 0.000340 & \pm 0.000207 & \pm 0.000062 & \pm 8.20 \\
\hline \multirow[t]{2}{*}{ C/1947 Y1 } & 16481028 & 19480215.276061 & 1.49138818 & 0.99995691 & 62.089047 & 199.256479 & 77.586851 & 28.89 \\
\hline & & \pm 0.000370 & \pm 0.00000319 & \pm 0.00001267 & \pm 0.000218 & \pm 0.000073 & \pm 0.000061 & \pm 8.49 \\
\hline \multirow[t]{2}{*}{ C/1948 E1 } & 16471103 & 19480515.582710 & 2.09496271 & 0.99992197 & 67.168988 & 247.706993 & 92.925547 & 37.25 \\
\hline & & \pm 0.000303 & \pm 0.00000240 & \pm 0.00000575 & \pm 0.000127 & \pm 0.000044 & \pm 0.000034 & \pm 2.74 \\
\hline \multirow[t]{2}{*}{ C/1948 T1 } & 16450206 & 19470903.743055 & 3.26052435 & 0.99988853 & 73.395315 & 121.990438 & 155.123775 & 34.19 \\
\hline & & \pm 0.010324 & \pm 0.00011080 & \pm 0.00003277 & \pm 0.001840 & \pm 0.000217 & \pm 0.000260 & \pm 10.05 \\
\hline \multirow{2}{*}{ C/1950 K1 } & 16490804 & 19510115.032274 & 2.57130432 & 0.99988404 & 192.367874 & 38.749976 & 144.145001 & 45.10 \\
\hline & & \pm 0.000373 & \pm 0.00000141 & \pm 0.00000560 & \pm 0.000093 & \pm 0.000047 & \pm 0.000031 & \pm 2.18 \\
\hline
\end{tabular}




\section{Appendix E: Future barycentric orbital elements}

Table E.1. Orbital elements of future barycentric orbits, that is, after suffering the planetary perturbations for all models described in Table C.1.

\begin{tabular}{|c|c|c|c|c|c|c|c|c|}
\hline Comet & $\begin{array}{c}\text { Epoch } \\
\text { [yyyymmdd] } \\
(2)\end{array}$ & $\begin{array}{r}T \\
\text { [yyyymmdd.dddddd] } \\
(3)\end{array}$ & $\begin{array}{r}q \\
{[\mathrm{AU}]} \\
(4)\end{array}$ & (5) & $\begin{array}{l}\omega \\
{\left[{ }^{\circ}\right]} \\
(6)\end{array}$ & $\begin{array}{l}\Omega \\
{\left[{ }^{\circ}\right]} \\
(7)\end{array}$ & $\begin{array}{r}i \\
{\left[{ }^{\circ}\right]} \\
(8)\end{array}$ & $\begin{array}{r}1 / a_{\text {fut }} \\
{\left[10^{-6} \mathrm{AU}^{-1}\right]} \\
(9)\end{array}$ \\
\hline \multirow[t]{2}{*}{ C/1902 R1 } & 22100426 & 19021124.008464 & 0.40184116 & 0.99965002 & 152.815403 & 50.627736 & 156.403506 & 870.94 \\
\hline & & \pm 0.000019 & \pm 0.00000033 & \pm 0.00000069 & \pm 0.000086 & \pm 0.000088 & \pm 0.000037 & \pm 1.71 \\
\hline \multirow[t]{2}{*}{$\mathrm{C} / 1902 \mathrm{X} 1$} & 21990801 & 19030323.651406 & 2.78159684 & 1.00122340 & 5.932702 & 118.796694 & 43.858159 & -439.82 \\
\hline & & \pm 0.002538 & \pm 0.00001339 & \pm 0.00002014 & \pm 0.000770 & \pm 0.000085 & \pm 0.000262 & \pm 7.24 \\
\hline \multirow[t]{2}{*}{ C/1903 M1 } & 21900120 & 19030828.359623 & 0.33314041 & 1.00033647 & 127.333709 & 295.030879 & 84.934214 & -1010.01 \\
\hline & & \pm 0.000136 & \pm 0.00000153 & \pm 0.00000318 & \pm 0.000266 & \pm 0.000058 & \pm 0.000200 & \pm 9.55 \\
\hline \multirow[t]{2}{*}{ C/1904 Y1 } & 22080725 & 19041104.322846 & 1.88304686 & 0.99934541 & 40.729565 & 219.768501 & 99.640020 & 347.62 \\
\hline & & \pm 0.013289 & \pm 0.00010131 & \pm 0.00022098 & \pm 0.006727 & \pm 0.000580 & \pm 0.000593 & \pm 117.37 \\
\hline \multirow[t]{4}{*}{ C/1906 B1 } & 22000329 & 19051224.093101 & 1.28893207 & 1.00051887 & 89.763925 & 287.836952 & 126.593908 & -402.56 \\
\hline & & \pm 0.000459 & \pm 0.00000338 & \pm 0.00002960 & \pm 0.000344 & \pm 0.000313 & \pm 0.000199 & \pm 22.96 \\
\hline & 22021224 & 19051224.081525 & 1.28876275 & 1.00019277 & 89.750691 & 287.838945 & 126.593965 & -149.58 \\
\hline & & \pm 0.003074 & \pm 0.00004399 & \pm 0.00009521 & \pm 0.003441 & \pm 0.000635 & \pm 0.000194 & \pm 73.87 \\
\hline \multirow[t]{2}{*}{ C/1906 E1 } & 22020319 & 19051017.757182 & 3.34445809 & 1.00177097 & 158.629204 & 343.663142 & 4.280140 & -529.52 \\
\hline & & \pm 0.001897 & \pm 0.00001428 & \pm 0.00001853 & \pm 0.000819 & \pm 0.000733 & \pm 0.000190 & \pm 5.54 \\
\hline \multirow[t]{2}{*}{ C/1907 E1 } & 22040131 & 19070320.176742 & 2.04521487 & 1.00057480 & 317.069049 & 98.573559 & 141.673192 & -281.04 \\
\hline & & \pm 0.001723 & \pm 0.00001627 & \pm 0.00004407 & \pm 0.000814 & \pm 0.000221 & \pm 0.000193 & \pm 21.54 \\
\hline \multirow{4}{*}{ C/1911 S3 } & 22090720 & 19111011.596948 & 0.30043610 & 0.99997575 & 71.589527 & 89.279608 & 96.563646 & 80.70 \\
\hline & & \pm 0.000548 & \pm 0.00000079 & \pm 0.00001106 & \pm 0.000386 & \pm 0.000422 & \pm 0.000553 & \pm 36.80 \\
\hline & 22210227 & 19111011.613216 & 0.30042613 & 0.99968737 & 71.591551 & 89.281396 & 96.569195 & 1040.62 \\
\hline & & \pm 0.003643 & \pm 0.00000226 & \pm 0.00006152 & \pm 0.000534 & \pm 0.000529 & \pm 0.001329 & \pm 204.78 \\
\hline \multirow{2}{*}{ C/1912 R1 } & 22060517 & 19121005.284559 & 0.71584674 & 1.00026544 & 25.598506 & 298.263151 & 79.808281 & -370.81 \\
\hline & & \pm 0.000055 & \pm 0.00000088 & 0377 & \pm 0.000110 & 00111 & 0084 & \pm 5.27 \\
\hline \multirow[t]{4}{*}{ C/1913 Y1 } & 22131027 & 19141026.924754 & 1.10518625 & 0.99993766 & 97.460986 & 60.292940 & 82189 & 56.41 \\
\hline & & \pm 0.000074 & \pm 0.00000079 & \pm 0.00000143 & \pm 0.000028 & \pm 0.000024 & 0043 & \pm 1.30 \\
\hline & 22140224 & 19141026.924707 & 1.10515434 & 0.99990403 & 97.458874 & 60.292937 & 67.982497 & 86.84 \\
\hline & & \pm 0.000072 & \pm 0.00000460 & \pm 0.00000467 & \pm 0.000300 & \pm 0.000023 & \pm 0.000059 & \pm 4.23 \\
\hline \multirow{4}{*}{ C/1914 F1 } & 22310903 & 19140605.374133 & 1.18818561 & 0.99822733 & 71.900648 & 200.113641 & 23.956594 & 1491.91 \\
\hline & & \pm 0.000210 & \pm 0.00000581 & \pm 0.00003377 & \pm 0.000279 & \pm 0.000334 & \pm 0.000349 & \pm 28.43 \\
\hline & 22310506 & 19140605.383588 & 1.18811153 & 0.99824831 & 71.895811 & 200.118493 & 23.950336 & 1474.34 \\
\hline & & \pm 0.002600 & \pm 0.00001532 & \pm 0.00004474 & \pm 0.001262 & \pm 0.001861 & \pm 0.001799 & \pm 37.67 \\
\hline \multirow[t]{2}{*}{ C/1914 M1 } & 22170827 & 19140730.313104 & 3.74262397 & 0.99996809 & 13.874513 & 271.460496 & 71.079539 & 8.53 \\
\hline & & \pm 0.010833 & \pm 0.00006880 & \pm 0.00009356 & \pm 0.002108 & \pm 0.000169 & \pm 0.000423 & \pm 25.00 \\
\hline \multirow[t]{4}{*}{ C/1916 G1 } & 22260313 & 19170618.004132 & 1.68486080 & 0.99868344 & 120.734220 & 184.255647 & 25.636610 & 781.41 \\
\hline & & \pm 0.000249 & \pm 0.00000104 & \pm 0.00000539 & \pm 0.000142 & \pm 0.000054 & 00045 & \pm 3.20 \\
\hline & 22260313 & 19170618.002781 & 1.68482103 & 0.99867953 & 120.732445 & 184.255375 & 25.636480 & 783.75 \\
\hline & & \pm 0.000285 & \pm 0.00000571 & \pm 0.00 & 0275 & 0066 & 079 & \pm 8.79 \\
\hline \multirow[t]{2}{*}{ C/1919 Q2 } & 22171225 & 19191208.123284 & 1.11801549 & 1.00003007 & 185.783020 & 122.055357 & 46.365671 & -26.89 \\
\hline & & 2011 & \pm 0.00002841 & \pm 0.0 & 2443 & 0557 & 0179 & \pm 67.31 \\
\hline \multirow[t]{4}{*}{ C/1921 E1 } & 22140224 & 19210510.725714 & 1.00362490 & 1.00049067 & 64.338847 & 269.351069 & 132.108442 & -488.90 \\
\hline & & & \pm 0.00000145 & \pm 0.00003778 & \pm 0.000239 & \pm 0.000282 & \pm 0.000123 & \pm 37.64 \\
\hline & 22170320 & 19210510.725850 & 1.00355226 & 1.00021161 & 64.332073 & 269.349172 & 132.109300 & -210.87 \\
\hline & & \pm 0.001774 & \pm 0.00002192 & \pm 0.00009696 & \pm 0.002369 & \pm 0.000497 & \pm 0.000210 & \pm 96.61 \\
\hline \multirow[t]{2}{*}{ C/1922 U1 } & 22170320 & 19221026.356621 & 2.26579397 & 1.00122836 & 118.400924 & 221.526423 & 51.410666 & -542.13 \\
\hline & & \pm 0.001274 & \pm 0.00000754 & \pm 0.00001929 & \pm 0.000480 & \pm 0.000054 & \pm 0.000035 & \pm 8.51 \\
\hline C/1925 F1 & 22301127 & 19250905.761751 & 4.18479767 & 0.99946443 & 205.679732 & 358.527886 & 146.715638 & 127.98 \\
\hline & & \pm 0.004022 & \pm 0.00002335 & \pm 0.00003486 & \pm 0.000573 & \pm 0.000097 & \pm 0.000144 & \pm 8.33 \\
\hline C/1925 G1 & 22171006 & 19250401.599089 & 1.10790258 & 1.00058995 & 36.149443 & 319.121445 & 99.886189 & -532.49 \\
\hline & & \pm 0.000224 & \pm 0.00000311 & \pm 0.00000637 & \pm 0.000282 & \pm 0.000059 & \pm 0.000081 & \pm 5.74 \\
\hline C/1925 W1 & 22210518 & 19251003.313123 & 1.56877876 & 1.00049850 & 106.484194 & 335.500024 & 49.276562 & -317.76 \\
\hline & & & \pm 0.00001517 & \pm 0.00001508 & \pm 0.000597 & \pm 0.000042 & \pm 0.000414 & \pm 9.61 \\
\hline C/1932 M1 & 22290406 & 19320924.831765 & 1.64649976 & 1.00040467 & 69.763011 & 246.059025 & 78.330249 & -245.77 \\
\hline & & \pm 0.001018 & \pm 0.00001203 & \pm 0.00003194 & \pm 0.000641 & \pm 0.000225 & \pm 0.000200 & \pm 19.40 \\
\hline C/1932 M2 & 22300730 & 19320921.652251 & 2.30775841 & 1.00052850 & 329.645277 & 216.182491 & 125.017993 & -229.01 \\
\hline & & & \pm 0.00000273 & \pm 0.00000709 & \pm 0.000144 & \pm 0.000058 & \pm 0.000050 & \pm 3.07 \\
\hline C/1935 Q1 & 22360807 & 19360511.495408 & 4.03970045 & 1.00115405 & 44.839534 & 300.607693 & 66.119413 & -285.68 \\
\hline & & \pm 0.001671 & \pm 0.00000994 & \pm 0.00002096 & \pm 0.000252 & \pm 0.000060 & \pm 0.000051 & \pm 5.19 \\
\hline C/1937 C1 & 22540505 & 19370620.739997 & 1.71646743 & 0.99760231 & 107.371079 & 128.427941 & 41.478490 & 1396.88 \\
\hline
\end{tabular}

Notes. The successive columns signify (1) - comet designation; (2) - epoch, that is, osculation date; (3) - perihelion time [TT]; (4) - perihelion distance; (5) - eccentricity; (6) - argument of perihelion (in degrees), equinox 2000.0; (7) - longitude of the ascending node (in degrees), equinox 2000.0; (8) - inclination (in degrees), equinox 2000.0; (9) - reciprocal future semi-major axis in units of $10^{-6} \mathrm{AU}^{-1}$. Future orbits determined using the NG model of motion are indicated by light grey shading. 
Table E.1. continued.

\begin{tabular}{|c|c|c|c|c|c|c|c|c|}
\hline Comet & $\begin{array}{c}\text { Epoch } \\
\text { [yyyymmdd] } \\
(2)\end{array}$ & $\begin{array}{r}T \\
\text { [yyyymmdd.dddddd] } \\
(3)\end{array}$ & $\begin{array}{r}q \\
\text { [AU] } \\
\text { (4) }\end{array}$ & (5) & $\begin{array}{l}\omega \\
{\left[{ }^{\circ}\right]} \\
(6)\end{array}$ & $\begin{array}{r}\Omega \\
{\left[{ }^{\circ}\right]} \\
(7)\end{array}$ & $\begin{array}{r}i \\
{\left[{ }^{\circ}\right]} \\
(8)\end{array}$ & $\begin{array}{r}1 / a_{\text {fut }} \\
{\left[10^{-6} \mathrm{AU}^{-1}\right]} \\
(9)\end{array}$ \\
\hline \multirow{3}{*}{ (1) } & & \pm 0.000458 & \pm 0.00000408 & \pm 0.00001230 & \pm 0.000299 & \pm 0.000104 & \pm 0.000083 & \pm 7.17 \\
\hline & 22540326 & 19370620.736751 & 1.71645095 & 0.99762556 & 107.368860 & 128.427721 & 41.478508 & 1383.34 \\
\hline & & \pm 0.001577 & \pm 0.00001050 & \pm 0.00002006 & \pm 0.001035 & \pm 0.000152 & \pm 0.000087 & \pm 11.69 \\
\hline \multirow[t]{4}{*}{ C/1937 N1 } & 22370911 & 19370815.710412 & 0.85988734 & 0.99983290 & 114.636164 & 59.325102 & 146.421365 & 194.32 \\
\hline & & \pm 0.000147 & \pm 0.00000043 & \pm 0.00003483 & \pm 0.000405 & \pm 0.000235 & \pm 0.000195 & \pm 40.51 \\
\hline & 22380218 & 19370815.715783 & 0.85990802 & 0.99980114 & 114.641669 & 59.325890 & 146.423252 & 231.25 \\
\hline & & \pm 0.001815 & \pm 0.00002536 & \pm 0.00014765 & \pm 0.002542 & \pm 0.000772 & \pm 0.000625 & \pm 171.71 \\
\hline \multirow{4}{*}{ C/1940 R2 } & 22210806 & 19410115.372565 & 0.37020628 & 1.00060367 & 199.642916 & 296.590685 & 49.670477 & -1630.62 \\
\hline & & \pm 0.000073 & \pm 0.00000271 & \pm 0.00000657 & \pm 0.000117 & \pm 0.000141 & \pm 0.000171 & \pm 17.75 \\
\hline & 22221129 & 19410115.373155 & 0.37020004 & 1.00055310 & 199.639408 & 296.591043 & 49.669507 & -1494.06 \\
\hline & & \pm 0.000183 & \pm 0.00000311 & \pm 0.00001323 & \pm 0.000646 & \pm 0.000184 & \pm 0.000154 & \pm 35.72 \\
\hline \multirow[t]{2}{*}{ C/1940 S1 } & 22310506 & 19400816.426110 & 1.05927916 & 1.00074474 & 329.790299 & 128.282572 & 133.042273 & -703.06 \\
\hline & & \pm 0.020134 & \pm 0.00042718 & \pm 0.00045228 & \pm 0.036971 & \pm 0.006163 & \pm 0.001158 & \pm 426.69 \\
\hline \multirow[t]{2}{*}{ C/1941 K1 } & 22410712 & 19410904.986298 & 0.86551738 & 0.99985613 & 85.103947 & 257.564985 & 94.558245 & 166.22 \\
\hline & & \pm 0.000077 & \pm 0.00000031 & \pm 0.00000213 & \pm 0.000038 & \pm 0.000024 & \pm 0.000108 & \pm 2.47 \\
\hline \multirow[t]{4}{*}{ C/1942 C1 } & 22320719 & 19420430.287518 & 1.44687232 & 1.00117778 & 223.445496 & 340.917068 & 79.307804 & -814.02 \\
\hline & & \pm 0.000120 & \pm 0.00000079 & \pm 0.00000482 & \pm 0.000077 & \pm 0.000017 & \pm 0.000063 & \pm 3.33 \\
\hline & 22321226 & 19420430.286227 & 1.44684302 & 1.00112229 & 223.443680 & 340.917930 & 79.307463 & -775.68 \\
\hline & & \pm 0.000390 & \pm 0.00001091 & \pm 0.00001243 & \pm 0.000555 & \pm 0.000293 & \pm 0.000203 & \pm 8.59 \\
\hline \multirow[t]{2}{*}{ C/1942 C2 } & 22430304 & 19420925.248677 & 4.10166979 & 1.00114131 & 163.296372 & 281.066902 & 172.512207 & -278.26 \\
\hline & & \pm 0.007699 & \pm 0.00003144 & \pm 0.00005528 & \pm 0.001447 & \pm 0.000849 & \pm 0.000123 & \pm 13.47 \\
\hline \multirow[t]{2}{*}{ C/1944 K2 } & 22390215 & 19440718.115518 & 2.22184587 & 1.00115253 & 336.928234 & 203.612746 & 94.989126 & -518.73 \\
\hline & & \pm 0.001858 & \pm 0.00001318 & \pm 0.00002848 & \pm 0.000683 & \pm 0.000193 & \pm 0.000156 & \pm 12.82 \\
\hline \multirow[t]{4}{*}{ C/1946 C1 } & 22500307 & 19460412.859596 & 1.72038322 & 0.99933427 & 54.182409 & 129.696232 & 72.941443 & 386.97 \\
\hline & & \pm 0.000352 & \pm 0.00000321 & \pm 0.00000791 & \pm 0.000211 & \pm 0.000055 & \pm 0.000056 & \pm 4.60 \\
\hline & 22490928 & 19460412.860782 & 1.72036623 & 0.99940339 & 54.181924 & 129.696514 & 72.941172 & 346.80 \\
\hline & & \pm 0.000603 & \pm 0.00000764 & \pm 0.00000964 & \pm 0.000402 & \pm 0.000053 & \pm 0.000055 & \pm 5.61 \\
\hline \multirow[t]{2}{*}{ C/1946 P1 } & 22450621 & 19461026.922779 & 1.13244087 & 0.99997447 & 320.262683 & 238.420478 & 56.958209 & 22.55 \\
\hline & & \pm 0.000509 & \pm 0.00000300 & \pm 0.00000575 & \pm 0.000284 & \pm 0.000193 & \pm 0.000063 & \pm 5.08 \\
\hline \multirow[t]{4}{*}{ C/1946 U1 } & 22471228 & 19470207.503759 & 2.41255932 & 0.99993675 & 348.625816 & 35.533705 & 108.158906 & 26.22 \\
\hline & & \pm 0.000434 & \pm 0.00000210 & \pm 0.00001094 & \pm 0.000140 & \pm 0.000048 & \pm 0.000048 & \pm 4.54 \\
\hline & 22480317 & 19470207.500365 & 2.41252207 & 0.99989415 & 348.624376 & 35.533900 & 108.158812 & 43.88 \\
\hline & & \pm 0.001228 & \pm 0.00001314 & \pm 0.00001573 & \pm 0.000512 & \pm 0.000069 & \pm 0.000051 & \pm 6.52 \\
\hline \multirow[t]{4}{*}{ C/1947 S1 } & 22411219 & 19480216.805182 & 0.74487969 & 1.00026541 & 350.247822 & 271.579999 & 140.472078 & -356.31 \\
\hline & & \pm 0.000086 & \pm 0.00000076 & \pm 0.00000258 & \pm 0.000181 & \pm 0.000231 & \pm 0.000079 & \pm 3.46 \\
\hline & 22420925 & 19480216.803521 & 0.74482539 & 1.00020675 & 350.241846 & 271.579407 & 140.472235 & -277.59 \\
\hline & & \pm 0.000310 & \pm 0.00000550 & \pm 0.00000870 & \pm 0.000620 & \pm 0.000206 & \pm 0.000061 & \pm 11.68 \\
\hline \multirow[t]{2}{*}{ C/1947 Y1 } & 22471009 & 19480216.304140 & 1.49784258 & 0.99991866 & 61.829573 & 199.327504 & 77.567907 & 54.31 \\
\hline & & \pm 0.000211 & \pm 0.00000338 & \pm 0.00001273 & \pm 0.000217 & \pm 0.000072 & \pm 0.000061 & \pm 8.50 \\
\hline \multirow{2}{*}{ C/1948 E1 } & 22481112 & 19480516.423445 & 2.10546507 & 0.99992587 & 66.831432 & 247.667975 & 92.893283 & 35.21 \\
\hline & & \pm 0.000277 & \pm 0.00000244 & \pm 0.00000577 & \pm 0.000127 & \pm 0.000044 & \pm 0.000033 & \pm 2.74 \\
\hline \multirow[t]{2}{*}{$\mathrm{C} / 1948 \mathrm{~T} 1$} & 22520624 & 19470903.674841 & 3.27021985 & 0.99926416 & 73.548717 & 122.147554 & 155.105084 & 225.01 \\
\hline & & \pm 0.010358 & \pm 0.00011088 & \pm 0.00003285 & \pm 0.001821 & \pm 0.000214 & \pm 0.000259 & \pm 10.05 \\
\hline \multirow[t]{2}{*}{$\mathrm{C} / 1950 \mathrm{~K} 1$} & 22550321 & 19510114.572471 & 2.57371784 & 0.99928354 & 192.416020 & 38.885979 & 144.138428 & 278.37 \\
\hline & & \pm 0.000396 & \pm 0.00000139 & \pm 0.00000561 & \pm 0.000093 & \pm 0.000048 & \pm 0.000031 & \pm 2.18 \\
\hline
\end{tabular}

